\title{
ARIANA SOARES RODRIGUES
}

Efeitos clínicos e microbiológicos, pela PCR em tempo real, do tratamento não-cirúrgico da Periodontite Agressiva, associado ao uso de amoxicilina e metronidazol

São Paulo 


\section{ARIANA SOARES RODRIGUES}

Efeitos clínicos e microbiológicos, pela PCR em tempo real, do tratamento não-cirúrgico da Periodontite Agressiva, associado ao uso de amoxicilina e metronidazol

Versão Original

Tese apresentada à Faculdade de Odontologia da Universidade de São Paulo para obter do título de Doutor, pelo Programa de Pós-Graduação em Ciências Odontológicas.

Área de Concentração: Periodontia

Orientador: Prof. Dr. Giorgio De Micheli

São Paulo 
Autorizo a reprodução e divulgação total ou parcial deste trabalho, por qualquer meio convencional ou eletrônico, para fins de estudo e pesquisa, desde que citada a fonte.

\author{
Catalogação da Publicação \\ Serviço de Documentação Odontológica \\ Faculdade de Odontologia da Universidade de São Paulo
}

Rodrigues, Ariana Soares

Efeitos clínicos e microbiológicos, pela PCR em tempo real, do tratamento nãocirúrgico da periodontite agressiva, associado ao uso de amoxicilina e metranidazol [versão original] / Ariana Soares Rodrigues; orientador Giorgio De Micheli. -- São Paulo, 2011.

$$
\text { 72p. : fig., tab.; } 30 \mathrm{~cm} \text {. }
$$

Tese -- Programa de Pós-Graduação em Ciências Odontológicas. Área de Concentração: Periodontia. -- Faculdade de Odontologia da Universidade de São Paulo.

1. Tratamento periodontal - Efeitos clínicos e microbiológicos. 2. Periodontite agressiva - Medicamentos. 3. Reação em cadeia por Polimerase. I. De Micheli, Giorgio. II. Título. 
Rodrigues AS. Efeitos clínicos e microbiológicos, pela PCR em tempo real, do tratamento não-cirúrgico da Periodontite Agressiva, associado ao uso de amoxicilina e metronidazol. Tese apresentada à Faculdade de Odontologia da Universidade de São Paulo para obtenção do título de Doutor em Ciências Odontológicas. Versão Original.

Aprovado em: / /2011

\section{Banca Examinadora}

$\operatorname{Prof}(a) . \operatorname{Dr}(a)$ Instituição:

Julgamento: Assinatura:

$\operatorname{Prof}(a) . \operatorname{Dr}(a)$. Instituição:

Julgamento: Assinatura:

Prof(a). Dr(a). Instituição:

Julgamento: Assinatura:

Prof(a). Dr(a). Instituição:

Julgamento: Assinatura:

Prof(a). Dr(a). Instituição:

Julgamento: Assinatura: 
Aos meus queridos pais

Malvino e Marisa, pelo apoio e confiança que me dão, em todos os momentos da minha vida; por terem me dado uma ótima criação e pelos valores que me transmitiram; amo vocês, incondicionalmente;

Ao meu marido

Fernando,

amigo e companheiro em todas as horas; meu colega, que me ajudou muito na elaboração deste trabalho; meu amor, que me deu o que eu tenho de mais importante nesta vida, nosso filho;

Ao meu filho

Enrico,

meu maior sonho realizado.

Dedico carinhosamente este trabalho 


\section{AGRADECIMENTOS ESPECIAIS}

Aos meus sogros, MARY e MARCOS, e à minha irmã, TICIANA, que muito me ajudaram ao cuidarem de meu filho, possibilitando a realização deste trabalho.

Ao querido Prof. Dr. ROBERTO FRAGA MOREIRA LOTUFO (in memorian), idealizador desta pesquisa, por quem sempre tive muito carinho e respeito, cujos ensinamentos, alegria e perseverança permanecerão para sempre em minha memória.

Ao Prof. Titular MARIO HIROYUKI HIRATA, que nos recebeu com muito respeito e nos abriu as portas de seu laboratório, que muito me ensinou neste produtivo período em que convivemos. Agradeço pela grande oportunidade de aprendizado e por ter confiado em nosso trabalho. 


\section{AGRADECIMENTOS}

Ao meu orientador Prof. Dr. GIORGIO DE MICHELI, que teve uma presença muito importante em minha formação. Agradeço sua confiança, segurança e apoio constantes.

À colega DANIELLE SALAMI LOURENÇÃO, pela amizade, pelo trabalho em conjunto e apoio mútuo durante a execução deste trabalho.

Ao Prof. Dr. CLÁUDIO MENDES PANNUTI que colaborou neste trabalho e por quem tenho grande admiração como profissional e como pessoa.

Ao Prof. Titular FRANCISCO EMÍLIO PUSTIGLIONI, pelo importante trabalho na Disciplina de Periodontia da FOUSP.

Aos Professores da Disciplina de Periodontia da FOUSP, Prof. Associado CESÁRIO ANTONIO DUARTE, Prof. Associado LUÍS ANTÔNIO ALVES DE LIMA, Prof. Associado GIUSEPPE ALEXANDRE ROMITO, Prof. Dr. KOTO NAKAE, Prof. Dr. JOÃO BATISTA C. NETO, Prof. Dr. MARCO ANTÔNIO P. GEORGETTI, Profa. Dra. MARINA CLEMENTE CONDE, Profa. Dra. LUCIANA SARAIVA DE CAMPOS e Profa. Dra. MARINELLA HOLZHAUSEN, pessoas por quem tenho grande admiração e respeito.

À Profa. Titular ROSÁRIO D. CRESPO HIRATA, pela colaboração no desenvolvimento desse trabalho.

Ao Prof. Dr. NILTON E. LINCOPAN HUENUMAN, pela colaboração com a cultura das cepas bacterianas.

Aos colegas do Laboratório de Biologia Molecular da FCF-USP, em especial ao LÍDIO G. LIMA NETO, à VIVIAN N. SILBIGER e ao ANDRÉ D. LUCHESSI que, direta ou indiretamente, ajudaram muito na elaboração deste trabalho.

À técnica do Laboratório de Biologia Molecular da FCF-USP, CRISTINA FAJARDO, pela gentileza e apoio durante a utilização do laboratório.

Aos colegas dos cursos de especialização em Periodontia do SOESP e da ABENO, por terem aceitado as minhas ausências. 
Aos colegas da Disciplina de Periodontia da FOUSP pela adorável convivência.

Às secretárias da Disciplina de Periodontia da FOUSP, MÁRCIA e MARÍLIA, pela ajuda e disponibilidade sempre que precisei.

Às funcionárias da biblioteca da FOUSP, GLAUCI e VÂNIA, que me ajudaram nas correções finais e formatação desta tese. 


\section{RESUMO}

Rodrigues AS. Efeitos clínicos e microbiológicos, pela PCR em tempo real, do tratamento não-cirúrgico da Periodontite Agressiva, associado ao uso de amoxicilina e metronidazol [tese]. São Paulo: Universidade de São Paulo, Faculdade de Odontologia; 2011. Versão Original.

Objetivo: avaliar as alterações clínicas e microbiológicas resultantes do tratamento periodontal não-cirúrgico associado ao uso de amoxicilina e de metronidazol, em indivíduos portadores de periodontite agressiva (PA), pela qPCR. Material e métodos: 15 indivíduos com PA receberam tratamento periodontal não-cirúrgico e, 45 dias após o término do tratamento, foram medicados com os antimicrobianos. Dados clínicos e amostras de biofilme subgengival foram coletados no dia do exame inicial, 45 dias após o término do tratamento periodontal não-cirúrgico e 1 mês após o uso dos antimicrobianos. Após 3 e 6 meses, apenas novos dados clínicos foram coletados. A presença e a quantificação das bactérias Aggregatibacter actinomycetemcomitans, Porphyromonas gingivalis, Tannerella forsythensis, Treponema denticola e Dialister pneumosintes foram determinadas através da PCR em tempo real. Resultados: Todos os parâmetros clínicos, com exceção do nível clínico de inserção, melhoraram significativamente $(p<0,05)$ no $3^{\text {o. }}$ mês após a terapia não-cirúrgica associada com antibióticos. Houve redução significante $(p<0,05)$ nas quantidades de T.d. e T.f.. Após 1 mês, houve reduções significativas $(p<0,05)$ nas freqüências de P.g. e de T.f.. Conclusões: $O$ tratamento mecânico não-cirúrgico, associado ao uso de amoxicilina e metronidazol, levou à melhora de todos os parâmetros clínicos estudados, exceto do nível clínico de inserção, e reduziu significativamente as quantidades subgengivais de T.f. e T.d..

Palavras-chave: Periodontite agressiva. Reação em cadeia da polimerase. Microbiologia. Agentes antimicrobianos. Amoxicilina. Metronidazol. 


\begin{abstract}
Rodrigues AS. Clinical and microbiological effects, by real-time PCR, of nonsurgical treatment of aggressive periodontitis associated with the use of amoxicillin and metronidazole [thesis]. São Paulo: Universidade de São Paulo, Faculdade de Odontologia; 2011. Original Version.
\end{abstract}

Objective: To evaluate the clinical and microbiological changes resulting from nonsurgical periodontal treatment associated with amoxicillin and metronidazole, in individuals with aggressive periodontitis (AgP), by qPCR. Methods: 15 subjects with $\mathrm{AgP}$ received non-surgical periodontal treatment and 45 days after completion of treatment, were treated with antibiotics. Clinical data and samples of subgingival plaque were collected at baseline, 45 days after the non-surgical periodontal treatment and 1 month after the use of antimicrobials. After 3 and 6 months, only clinical data were collected. The presence and quantification of Aggregatibacter actinomycetemcomitans, Porphyromonas gingivalis, Tannerella forsythensis, Treponema denticola and Dialister pneumosintes were determined by real-time PCR. Results: All clinical parameters, with the exception of clinical attachment level (CAL), have significantly $(p<0,05)$ improved at the $3^{\text {th }}$ month after non-surgical therapy associated with antibiotics. There was significant $(p<0,05)$ reduction in the quantities of T.d. and T.f.. After one month, there were significant $(p<0,05)$ reductions in the frequencies of P.g. and T.f. Conclusions: The non-surgical mechanical treatment associated with the use of amoxicillin and metronidazole led to an improvement in all clinical parameters studied, except for clinical attachment level, and significantly reduced the amount of subgingival T.f. and T.d..

Keywords: Aggressive periodontitis. Polymerase Chain Reaction. Microbiology. Anti-bacterial agents. Amoxicillin. Metronidazole. 


\section{LISTA DE TABELAS}

Tabela 4.1 - Cepas Bacterianas

Tabela 4.2 - Iniciadores utilizados na reação da PCR .35

Tabela 4.3 - Sondas TaqMan® utilizadas na PCR em tempo real

Tabela 5.1 - Características demográficas 43

Tabela 5.2 - Parâmetros clínicos dos sujeitos de pesquisa no início, reavaliação, 1, 3 e 6 meses após antibiótico. . .44

Tabela 5.3 - Número de bactérias $\left(\times 10^{4}\right)$ nos momentos experimentais .45

Tabela 5.4 - Freqüência das bactérias nos momentos experimentais 46 


\section{LISTA DE ABREVIATURAS E SIGLAS}

AAP

A.a.

ATCC

BLAST

$\mathrm{CaCl}_{2}$

$\mathrm{C} t$

DMSO

DNA

dNTP

D.p.

$\mathrm{DP}$

E. coli

EDTA

$\mathrm{HCl}$

$\mathrm{KCl}$

$\mathrm{MgCl}_{2}$

$(\mathrm{NH} 4)_{2} \mathrm{SO}_{4}$

PBS

P.g.

$\mathrm{pH}$

qPCR

rRNA

TBE

T.d.

T.f.

UV
Academia Americana de Periodontia

Aggregatibacter (ou Actinobacillus) actinomycetemcomitans

American Type Culture Collection

Basic Local Alignment Search Tool

Cloreto de cálcio

Cycle threshold / ciclo limiar

Dimetilsulfóxido

Ácido desoxirribonucléico

Desoxirribonucleotídeo trifosfatado

Dialister pneumosintes

Desvio-padrão

Escherichia coli

Ácido etilenodiamino tetra-acético

Ácido clorídrico

Cloreto de potássio

Cloreto de magnésio

Sulfato de amônio

Phosphate-buffered saline / tampão salino fosfato

Porphyromonas gingivalis

Potencial hidrogeniônico

Reação em cadeia da polimerase quantitativa

Ribosomal ribonucleic acid / ácido ribonucléico ribossômico

Tampão borato EDTA

Treponema denticola

Tannerella forsythia

Ultravioleta 


\section{LISTA DE SÍMBOLOS}

$g$

$\mu \mathrm{L}$

$\mu \mathrm{g}$

$\mathrm{mg}$

$\mathrm{mL}$

$\mathrm{mm}$

$\mathrm{mM}$

$\mathrm{nm}$

$\mathrm{nM}$

${ }^{\circ} \mathrm{C}$ unidade de medida referente a força centrífuga

unidade de medida referente a microlitro

unidade de medida referente a micrograma

unidade de medida referente a miligrama

unidade de medida referente a mililitro

unidade de medida referente a milímetro

unidade de medida referente a milimolar

unidade de medida referente a nanômetro

unidade de medida referente a nanomolar

unidade de medida referente a Graus Celsius 


\section{SUMÁRIO}

1 INTRODUÇÃO

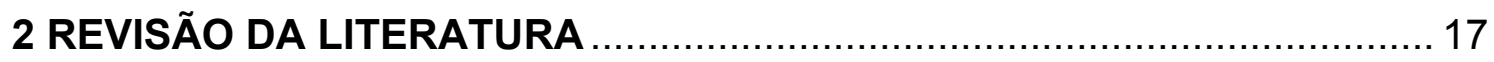

2.1 CLASSIFICAÇÃO E ETIOLOGIA DA PERIODONTITE AGRESSIVA ........ 17

2.2 PAPEL DOS MICRORGANISMOS NA PERIODONTITE AGRESSIVA ..... 18

2.3 EFEITOS E FORMAS DE TRATAMENTO DA PERIODONTITE

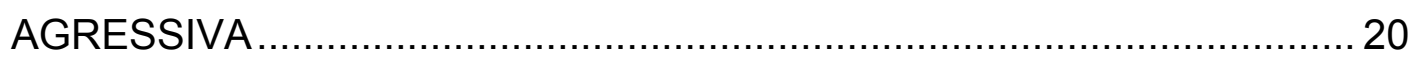

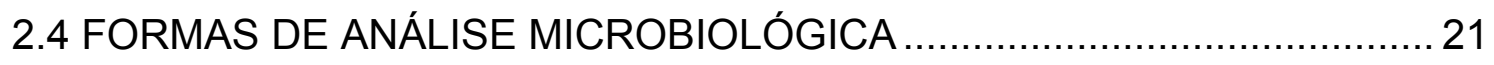

2.4.1 Microscopia de Fase ou de Campo Escuro .................................... 21

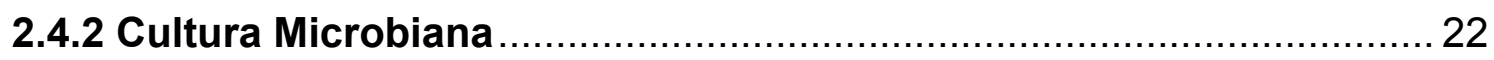

2.4.3 Métodos Baseados em Diagnósticos Imunológicos ….................... 23

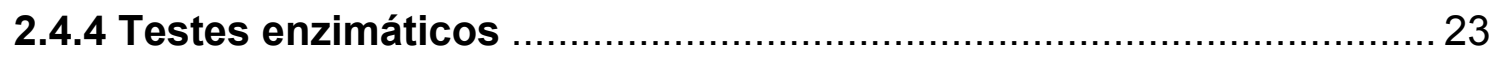

2.4.5 Sondas de ácido nucléico (sondas de DNA) …............................. 24

2.4.6 Detecção por hibridização DNA-DNA checkerboard ......................... 24

2.4.7 Reação em cadeia pela polimerase (PCR) ….................................. 25

2.4.8 PCR quantitativa (PCR em tempo real, qPCR) .............................. 26

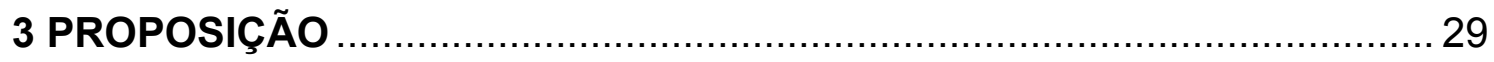

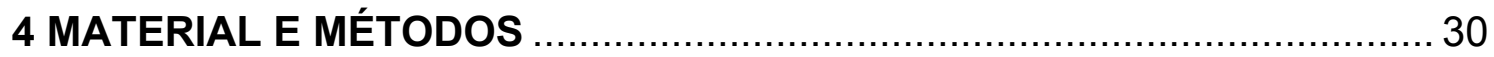

4.1 DELINEAMENTO DO ESTUDO E CASUÍSTICA...................................... 30

4.2 OBTENÇÃO DOS PARÂMETROS CLÍNICOS ......................................... 30

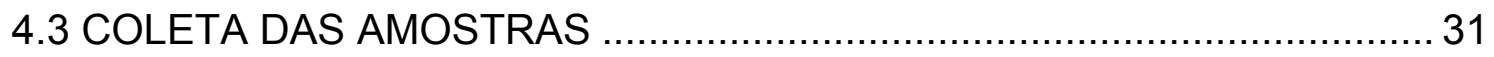

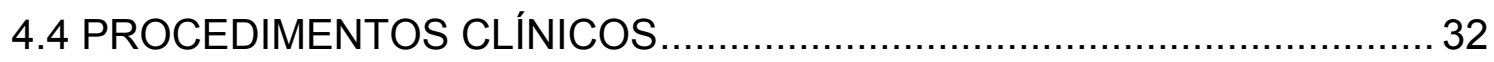

4.5 REALIZAÇÃO DA REAÇÃO EM CADEIA PELA POLIMERASE EM

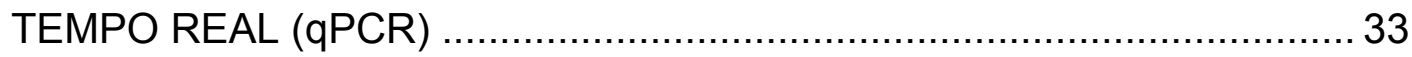

4.5.1 Procedimento para obtenção de controle interno para

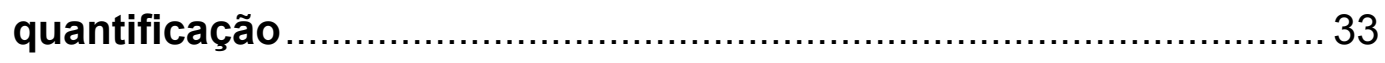

4.5.1.1 Extração de DNA das cepas bacterianas.......................................... 33

4.5.1.2 PCR para amplificação de fragmentos de DNA das bactérias $A$. a.,

P. g., T. d., T. f. e D. p., para clonagem ........................................... 34

4.5.1.3 Purificação dos produtos da PCR para clonagem ............................... 36 
4.5.1.4 Reação de ligação dos fragmentos dos genes obtidos pela PCR

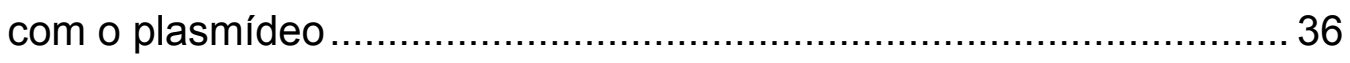

4.5.1.5 Preparação das bactérias competentes .......................................... 36

4.5.1.6 Transformação da E. coli com o plasmídeo recombinante ................... 37

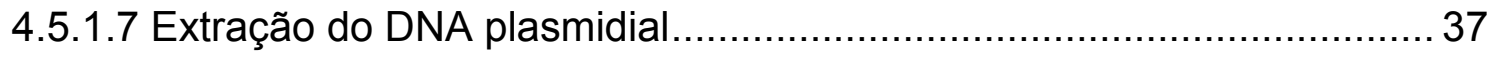

4.5.1.8 Análise do controle exógeno para quantificação do número de

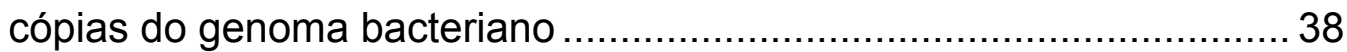

4.5.2 Preparo das amostras biológicas para extração de DNA ………....... 39

4.5.3 Reação em cadeia pela polimerase em tempo real (PCR em tempo

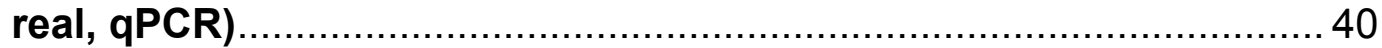

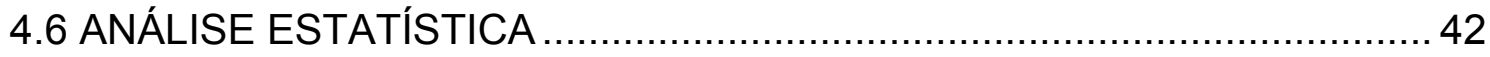

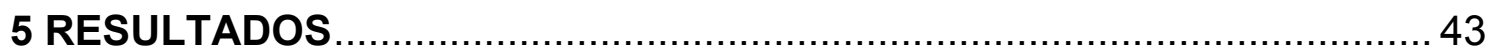

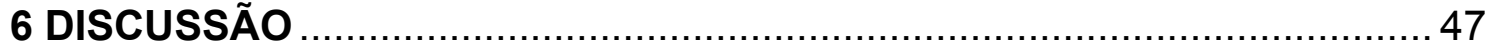

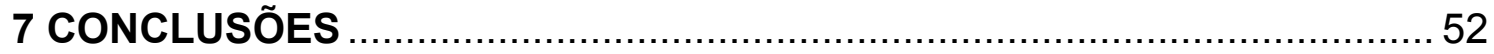

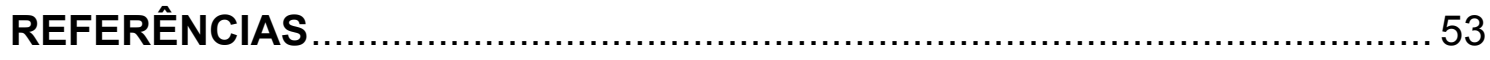

ANEXOS 


\section{INTRODUÇÃO}

A doença periodontal é uma doença infecciosa causada por um grande número de espécies bacterianas que podem atuar isoladamente ou em associação (Löe; Silness, 1963). O papel dos microrganismos no início e no desenvolvimento das doenças periodontais sempre foi objeto de estudos na área da Periodontia. Atualmente, considera-se que dentro da múltipla variedade de microrganismos presentes na cavidade bucal, alguns grupos bacterianos são relacionados a condições clínicas específicas da doença periodontal (Loesche, 1976; Newman et al., 1976; Slots, 1977, 2002; Colombo et al., 2009).

A cavidade bucal é colonizada por uma grande variedade de microrganismos. Aproximadamente 500 espécies diferentes de bactérias podem ser encontradas no ambiente subgengival (Paster et al., 2001). As bactérias Porphyromonas gingivalis, Tannerella forsythia e Aggregatibacter actinomycetemcomitans têm sido relacionadas com a progressão da doença periodontal (Ashimoto et al., 1996; Umeda et al., 1998; Socransky et al., 1998; Xymenez-Fyvie et al., 2000; Socransky et al., 2002), e são consideradas verdadeiros patógenos periodontais (Genco et al., 1996). Treponema denticola faz parte do complexo vermelho (Socransky et al., 1998) e está relacionada à periodontite crônica e progressão da doença periodontal, além de ter moderada evidência científica sobre seu papel na etiologia da doença periodontal (Genco, 1996). Vários estudos têm sugerido a inclusão da bactéria Dialister pneumosintes no grupo dos suspeitos patógenos devida à sua alta prevalência nas lesões periodontais avançadas (Moore; Moore, 1994a; Moore; Moore, 1994b; Contreras et al., 2000; Doan et al., 2000; Ghayoumi et al., 2002).

Sabe-se que a realização de raspagem e alisamento radicular, supra e subgengivais e controle mecânico do biofilme dental são essenciais no tratamento das doenças periodontais, trazendo bons resultados clínicos, principalmente em casos de gengivite e periodontite crônica (Baderstein et al., 1981; Pihlstrom et al., 1983; Lindhe; Nyman, 1984; Slots et al., 1990). Mas, nos casos mais graves de periodontite, os resultados do tratamento mecânico não-cirúrgico nem sempre são 
suficientes (AAP, 2000; Winkel et al., 2001; Haffajee et al., 2003). Nestes casos, os antibióticos podem ser usados como coadjuvantes ao tratamento, com o objetivo de eliminar ou diminuir a quantidade de microrganismos específicos e melhorar os parâmetros clínicos, principalmente nos casos de periodontite agressiva (Zambon et al., 1986; van Winkelhoff et al., 1989; de Graaf et al., 1989; Slots, 2002; Slots; Ting, 2002; Slots; Jorgensen, 2002; Preshaw, 2004; AAP, 2004; Mombelli; Samaranayake, 2004; Tonetti; Mombelli, 2010). Existe um consenso na literatura de que antibioticoterapia coadjuvante ao tratamento periodontal deve estar fundamentada em uma avaliação laboratorial microbiológica para adequar o tratamento da infecção periodontal presente ao uso de um antibiótico específico (Slots, 2002; AAP, 2004; Beikler et al., 2004). E que o momento mais adequado para a administração do medicamento é após a realização dos procedimentos de raspagem e aplainamento radicular e desorganização do biofilme subgengival, ou seja, na fase de reavaliação do tratamento periodontal, pois, nesta etapa, estariam presentes subgengivalmente apenas os microrganismos que foram resistentes ao tratamento mecânico, propiciando uma indicação mais específica da medicação (van Winkelhoff et al., 1996; Socransky; Haffajee, 2002; AAP, 2004; Preshaw, 2004; Tonetti; Mombelli, 2010).

No tratamento de periodontite agressiva, o antimicrobiano mais indicado e que apresentou melhores resultados na redução ou eliminação do principal periodontopatógeno associado à doença, o Aggregatibacter actinomycetemcomitans, e na melhora dos parâmetros clínicos, foi a associação de amoxicilina com metronidazol (van Winkelhoff et al., 1989; de Graaf et al., 1989; van Winkelhoff et al., 1992; Tinoco et al., 1998; Walker; Karpinia, 2002; Herrera et al., 2002; Beikler et al., 2004). Quando estes medicamentos são comparados com outros como azitromicina (Haas et al., 2008), doxiciclina (Machtei; Younis, 2008; Akincibay et al., 2008) e metronidazol (Xajigeorgeou et al., 2006; Feres, 2008) seus resultados são melhores ou semelhantes.

A avaliação dos efeitos microbiológicos do tratamento da periodontite agressiva associado ao uso de antibióticos já foi realizada utilizando-se a técnica de cultura (van Winkelhoff et al., 1989, 1992; Pavicic et al., 1994; Tinoco et al., 1998; Berglundh et al., 1998; Winkel et al., 2001), PCR específico ou hibridização 
DNA-DNA (Feres et al., 2001; Haffajee et al., 2004; Ehmke et al., 2005; Xajigeorgiou et al., 2006; Mestnik et al., 2010), por clonagem e sequenciamento de $16 S$ rRNA (Valenza et al., 2009). Mas, até o momento, pelo nosso conhecimento, não existem relatos na literatura desta avaliação através da PCR em tempo real.

Nota-se que as técnicas clássicas de microbiologia vem sendo substituídas, em alguns casos, pela detecção molecular (Reação em cadeia pela polimerase (PCR), hibridização DNA-DNA checkerboard, sondas de DNA, PCR em tempo real) e têm apresentado reconhecida superioridade em relação à microscopia de campo escuro e técnicas de cultura em termos de sensibilidade, especificidade e quantificação de microrganismos subgengivais (Boutaga et al., 2006; Jervøe Storm et al., 2005; Verner et al., 2006). Diversos estudos relataram a utilidade da PCR em tempo real para a quantificação de microrganismos incluindo bactérias e vírus (Lyons et al., 2000; Corless et al., 2001; Asai et al., 2002; Jebbink et al., 2003; Mackay, 2004). Esta técnica de biologia molecular também tem sido utilizada para quantificar a presença de periodontopatógenos subgengivais (Boutaga et al., 2006; Kuboniwa et al., 2004; Jervøe -Storm et al., 2005; Verner et al., 2006).

No presente estudo, avaliamos as alterações nos parâmetros clínicos e microbiológicos, pela PCR em tempo real, ocorridas devido ao tratamento periodontal não-cirúrgico associado a amoxicilina e metronidazol, em indivíduos portadores de periodontite agressiva. 


\section{REVISÃO DA LITERATURA}

\subsection{CLASSIFICAÇÃO E ETIOLOGIA DA PERIODONTITE AGRESSIVA}

De acordo com a classificação das doenças e condições periodontais realizada e apresentada pela Academia Americana de Periodontia em 1999, o termo Periodontite de Início Precoce (PIP), designado para identificar formas de periodontites altamente destrutivas, foi substituído pelo termo Periodontite Agressiva. Essa classificação de 1999 substituiu os nomes das doenças que antes eram conhecidas como Periodontite Juvenil (PJ), localizada ou generalizada, que levavam em conta a idade dos pacientes, para Periodontite Agressiva (PA), localizada (L) ou generalizada (G).

Pela nova classificação, as principais características da doença são: história médica não-significativa; rápida perda de inserção e destruição óssea; concentração familiar dos casos. Algumas características secundárias da doença podem estar presentes: quantidades de acúmulos microbianos inconsistentes com a severidade da destruição tecidual; proporções elevadas de A.a. e, em algumas populações, de P.g.; fagócitos anormais; macrófagos com fenótipos hiperresponsivos; progressão contínua de perda de inserção e perda óssea.

O diagnóstico deve ser feito levando-se em conta os achados clínicos, radiográficos e dados históricos da doença. Assim, a PA compreende um grupo de formas de periodontites de progressão rápida, raras e freqüentemente graves, muitas vezes caracterizadas pela idade precoce da manifestação clínica e uma tendência distinta dos casos a se desenvolver em uma mesma família.

Este grupo de doenças abrange formas de periodontite heterogêneas quanto à apresentação clínica e resposta à terapia. As formas agressivas de periodontite são caracterizadas pela destruição severa e rápida dos tecidos de suporte periodontal, raras e freqüentemente graves, e geralmente acometem o indivíduo numa idade jovem (Tonetti; Mombelli, 2010). Essa agressividade e 
rapidez na destruição dos tecidos pode ser interpretada pela presença de microrganismos altamente virulentos ou de uma alta susceptibilidade do hospedeiro à doença, ou, o mais provável, uma combinação de ambos.

Sabe-se, também, que as diversas formas de doença periodontal apresentam microbiotas distintas (Genco et al., 1996). A etiologia da periodontite agressiva tem sido associada, há muito tempo, à presença da bactéria A.a., baseando-se em estudos que mostram a presença deste microrganismo com maior freqüência e em maior quantidade no ambiente subgengival de indivíduos portadores desta doença. Mas esta é uma questão ainda controversa, pois existem estudos que mostram a presença de PA mesmo em pacientes que não foram positivos para a presença de A.a., e existem pacientes portadores de A.a. mas que não apresentam anticorpos para o microrganismo. Daí, então, passa-se a considerar a resposta imunológica, ou susceptibilidade do indivíduo, à presença de certos microrganismos e ao desenvolvimento da doença periodontal como fatores que influenciam o acometimento e a severidade da doença.

Assim, as PA são doenças multifatoriais que se desenvolvem como um resultado de interações complexas entre os genes específicos do hospedeiro e o meio.

\subsection{PAPEL DOS MICRORGANISMOS NA PERIODONTITE AGRESSIVA}

Em 1996, Genco et al. apresentaram os principais patógenos periodontais, divididos em grupos determinados pelas evidências de suas patogenicidades. P.g., A.a. e T.f. foram os microrganismos mais associados à patogenia das doenças periodontais (DP). Campylobacter rectus, Eubacterium nodatum, Prevotella intermedia/nigrescens, Parvimonas micra, Streptococcus intermedius e Treponema denticola estavam moderadamente associados à patogenia da DP. E evidências iniciais foram encontradas para Eikenella corrodens, bastonetes entéricos, espécies de Pseudomonas, espécies de Selenomonas e espécies de 
Staphylococcus. Associaram apenas o A.a. aos casos de PA e P.g. e T.f. aos casos de periodontite crônica (PC).

Os estudos sobre microbiologia periodontal tiveram grandes avanços após 1996. Novas técnicas de análise microbiológica foram desenvolvidas, o que possibilitou a detecção de microrganismos que não podiam ser detectados em laboratório. As técnicas de biologia molecular, que detectam seqüencias específicas do DNA, possibilitaram a avaliação de um espectro maior de microrganismos presentes no ambiente subgengival. Com isso, atualmente, a lista de possíveis patógenos periodontais aumentou muito (Armitage, 2010).

Com relação aos microrganismos presentes na PA, podemos considerar apenas que A.a. aparece como importante periodontopatógeno na PAL. Já nos casos de PAG, a microbiota se parece mais com a da periodontite crônica (Faveri et al., 2009).

O papel do Dialister pneumosintes na PA não é claro, e poucos estudos fizeram este tipo de identificação (Contreras et al., 2000; Doan et al., 2000; Ghayoumi et al., 2002; Nonnenmacher et al., 2004; Nonnenmacher et al., 2005). Nonnenmacher et al. (2005) apresentaram maiores quantidades de D.p. na periodontite agressiva do que na periodontite crônica, mas Lourenção (2010), não encontrou diferenças nas quantidades subgengivais deste microrganismo em casos de PA, periodontite crônica e gengivite.

A maior sensibilidade das técnicas de biologia molecular tem mostrado que os principais periodontopatógenos podem ser encontrados nas diversas formas de doenças periodontais. O que passou-se a considerar, então, é que cada doença pode apresentar diferentes sorotipos da mesma bactéria (Cortelli et al., 2005) e, também, diferentes quantidades do microrganismo no ambiente subgengival (Lourenção, 2010).

A presença de vírus (citomegalovírus, herpesvírus e Epstein-Barr vírus) associada à PA também já foi estudada (Ting et al., 2000; Kubar et al., 2004; Slots, 2005) e a presença de citomegalovírus associada à presença de P.g. esteve fortemente associada à PAL em adolescentes afro-caribenhos (Michalowicz et al., 2000). 


\subsection{EFEITOS E FORMAS DE TRATAMENTO DA PERIODONTITE AGRESSIVA}

Os resultados clínicos desejados da terapia periodontal foram claramente definidos. Os parâmetros de sucesso do tratamento periodontal são (AAP, 2000):

- significante redução dos sinais clínicos de inflamação;

- redução nas profundidades clínicas de sondagem;

- estabilização ou ganho nos níveis clínicos de inserção;

- evidência radiográfica da resolução da lesão óssea;

- controle do biofilme dental compatível com saúde.

Já os resultados microbiológicos são bem menos definidos. Espera-se não somente a redução ou eliminação dos patógenos periodontais, mas, também, a manutenção ou aumento da quantidade de microrganismos associados à saúde (Socransky; Haffajee, 2010) . Além disso, essas mudanças na microbiota devem ser mantidas durante a vida do paciente caso se objetive prevenir episódios futuros da doença.

Revisões sistemáticas mostraram que ocorrem melhoras nos parâmetros clínicos quando o tratamento periodontal não-cirúrgico é associado ao uso de antibióticos sistêmicos (Herrera et al., 2002; Herrera et al., 2008; Haffajee et al., 2003), particularmente com relação ao ganho de inserção clínica (Haffajee et al., 2003) e em casos de periodontite agressiva (Haffajee et al., 2003). Nestes casos, a longo prazo, os resultados obtidos se mantém (Tinoco et al., 1998). Uma revisão sistemática da literatura (Herrera et al., 2008) concluiu que: se o uso de antibióticos sistêmicos está indicado como parte do tratamento periodontal, ele deve ser usado como adjunto ao tratamento mecânico; não existe um protocolo específico para o uso de antibióticos sistêmicos juntamente com o tratamento mecânico, mas existem evidências que sugerem que o início do uso do medicamento deve ocorrer, de preferência, no dia do término do desbridamento, que deve ser finalizado em um período curto e com qualidade adequada para que os resultados sejam melhores. 
O método de diagnóstico microbiológico mais utilizado nos estudos mais recentes que avaliaram o tratamento mecânico da periodontite agressiva foi o de hibridização DNA-DNA checkerboard (Heller et al., 2011; Novaes et al., 2011; Rosalem et al., 2011) e PCR (Yek et al., 2010; Mario et al., 2010; Castillo et al., 2011). Os estudos que utilizavam técnicas de cultura, normalmente procuravam avaliar apenas a presença ou eliminação de A.a. nos casos de PA (Zambon et al., 1986; Saarela et al., 1999).

\subsection{FORMAS DE ANÁLISE MICROBIOLÓGICA}

Ao se levar em consideração a complexidade microbiológica da doença periodontal, diversas técnicas foram e continuam sendo desenvolvidas e utilizadas com o intuito de detectar periodontopatógenos em amostras de biofilme subgengival (Lotufo et al., 2005).

\subsubsection{Microscopia de Fase ou de Campo Escuro}

Consiste em uma técnica que possibilita identificar visualmente o tamanho, a forma e a motilidade das bactérias presentes na amostra, diferenciando-as entre cocos, bastonetes e espiroquetas, móveis ou não-móveis, e, também, as proporções relativas entre os microrganismos (Zambon, 1997; Loomer, 2004). A partir disso, pode-se inferir a presença de morfotipos bacterianos, e não bactérias específicas. Alguns estudos mostraram uma relação entre a presença de cocos e bastonetes não-móveis com saúde, enquanto que espiroquetas e bastonetes móveis estão associados à doença (Listgarten; Levin, 1981; Armitage et al., 1982). Mas, através desta técnica, não é possível a identificação de Aggregatibacter actinomycetemcomitans, nem de Porphyromonas gingivalis, os principais patógenos periodontais, nem a determinação da sensibilidade antimicrobiana dos 
microrganismos identificados. A sua importância, portanto, fica restrita à motivação à higiene bucal pelo paciente, uma vez que o cirurgião-dentista pode ter um microscópio de campo escuro em seu consultório e mostrar ao paciente os microrganismos presentes no biofilme removido de seu dente, além de fazer uma comparação entre antes e depois do tratamento periodontal (Zambon; Haraszthy, 1995). Porém, a longo prazo, a simples avaliação microscópica não pode prever a recorrência de doença periodontal (Loomer, 2004).

\subsubsection{Cultura Microbiana}

Os métodos de cultura ainda são considerados "gold standard", ou métodos de referência, como meio de comparação entre outras técnicas (Sanz et al., 2004). Através desta técnica é possível cultivar um amplo espectro de microrganismos presentes no ambiente subgengival (Lotufo; Pannuti, 2001), servindo para uma identificação positiva dos periodontopatógenos através de meios seletivos ou nãoseletivos e/ou associados a outras técnicas bioquímicas (Loomer, 2004). Pode-se, então, determinar, através de observação da morfologia das colônias, da coloração de Gram e de testes bioquímicos específicos, o número total de colônias, as espécies bacterianas e as suas proporções relativas (Sanz et al., 2004). Por detectar apenas microrganismos vivos, seus resultados apresentam maior significado clínico (Chen; Slots, 1999).

Um dos incovenientes é seu baixo poder de detecção, gerando resultados falso-negativos quando comparados a outras técnicas mais sensíveis, além de algumas espécies bacterianas serem difíceis de cultivar, como espiroquetas e Tannerella forsythia. Sem dúvida, a maior vantagem da técnica de cultura sobre as outras técnicas de identificação microbiológica é a possibilidade de realização de antibiograma, com a determinação da sensibilidade antimicrobiana das bactérias encontradas, proporcionando uma correta seleção de antimicrobianos (Loomer, 2004). Atualmente, outras técnicas estão sendo estudadas para esse fim, como a 
Reação de Polimerase em Cadeia quantitativa em tempo-real (qPCR) (Rolain et al., 2004).

\subsubsection{Métodos Baseados em Diagnósticos Imunológicos}

A identificação bacteriana é feita utilizando-se anticorpos que reconhecem antígenos específicos de certas espécies bacterianas. Existem vários tipos de testes imunológicos no mercado, como: microscopia por imunofluorescência direta e indireta, ELISA, membrana de imuno-análise e aglutinação de látex (Greenstein, 1988; Lamster et al., 1993). Como vantagens, estes métodos apresentam maior sensibilidade e especificidade que a cultura para os microrganismos alvo, custo baixo, são rápidos de realizar (podem ser feitos no consultório), além de serem relativamente quantitativos. Mas, podem apresentar reação cruzada entre espécies bacterianas, os limites de detecção são baixos e não oferecem informações sobre sensibilidade antimicrobiana (Loomer, 2004; Sanz et al., 2004).

\subsubsection{Testes enzimáticos}

Os testes enzimáticos foram desenvolvidos para detectar enzimas semelhantes à tripsina, produzidas por algumas espécies bacterianas, como Treponema denticola, Tannerella forsythensis, Porphyromonas gingivalis e algumas espécies de Capnocytophaga. Quando uma amostra de biofilme apresentar alguma combinação destas bactérias, e for colocada em contato com o substrato $\mathrm{N}$-benzoyl-DL-arginine-2-naphthylamide (BANA), ocorre a quebra deste substrato, que adquire cor azul-escura, variando na tonalidade dependendo da proporção das bactérias.

Estudos mostraram uma correlação entre o teste BANA e a profundidade de sondagem e sangramento à sondagem em sítios com doença periodontal 
(Loesche et al., 1990), mas, Beck et al. (1990), não encontraram associação estatística entre este teste e a perda de inserção clínica. Seu valor diagnóstico é baixo devido à sua baixa confiabilidade e ao fato de não determinar qual a espécie bacteriana encontrada.

\subsubsection{Sondas de ácido nucléico (sondas de DNA)}

As sondas de DNA consistem em seqüências conhecidas de ácido nucléico com marcadores radioativos ou colorimétricos que hibridam as seqüências complementares de ácido nucléico no microrganismo correspondente. As seqüências das sondas podem ser inteiramente genômicas, seqüências aleatoriamente clonadas de ácido nucléico ou oligonucleotídeos sintéticos (conhecidas como sondas de 16S rRNA para microrganismos). Dentre as três, as sondas de oligonucleotídeos sintéticos são as mais específicas, com menor reação cruzada, pois são utilizados genes específicos às espécies bacterianas e, atualmente, são formadas por oligonucleotídeos que variam entre 20 a 30 nucleotídeos (Soder et al., 1993; Nicholl, 1994; Dawson et al., 1996).

Esta técnica é mais sensível, mais rápida e com custo menor que a cultura (Tsai et al., 2003) e pode identificar espécies de difícil cultivo. Não precisa da viabilidade dos microrganismos para a detecção e não possibilita a realização de antibiograma.

\subsubsection{Detecção por hibridização DNA-DNA checkerboard}

Esta técnica utiliza sondas de DNA marcadas com digoxigenina. Coloca-se, em linhas paralelas em uma membrana de nylon, DNA bacteriano de 28 amostras de biofilme dental, e duas linhas de DNA controle (misturas das espécies de microrganismos alvo a $10^{5}$ e $10^{6}$ ). Perpendicularmente às linhas, são colocadas 40 
sondas de DNA em tampão de hibridização, marcadas com digoxigenina. Após uma lavagem rigorosa, os sinais são detectados utilizando-se anticorpos para digoxigenina conjugados com fosfatase alcalina e substratos, que podem produzir tanto sinais quimioluminescentes quanto sinais fluorescentes. Esses sinais são vistos na intersecção entre linhas e colunas na membrana de nylon, e a intensidade do sinal está relacionada ao número de microrganismos da espécie na amostra. As imagens podem ser capturadas por filme ou sistemas de detecção ligados ao computador. Os sinais podem ser convertidos em contagens bacterianas por comparação com os controles presentes na mesma membrana (Socransky et al., 1994; Socransky; Haffajee, 1999; Feres; Gonçalves, 2001; Socransky et al., 2004). Possibilita, então, a detecção de até 40 espécies bacterianas, não sendo possível a detecção de microrganismos que não estejam no menu de sondas. É uma técnica de detecção rápida, de baixo custo e que permite a detecção de microrganismos difíceis de cultivar, além da avaliação de um maior número de amostras. Seu principal uso está na área de pesquisa, em pesquisas epidemiológicas e estudos ecológicos, devido à rapidez, à capacidade de detectar várias espécies de microrganismos em várias amostras ao mesmo tempo e à não necessidade de microrganismos viáveis para realização da técnica (Sanz et al., 2004).

\subsubsection{Reação em cadeia pela polimerase (PCR)}

A PCR é uma técnica molecular utilizada para a replicação do DNA, possibilitando a síntese de várias cópias de uma amostra de DNA, mesmo que muito pequena, em pouco tempo. Tem a capacidade de detectar um microrganismo alvo em baixas concentrações, com alta especificidade.

Um ciclo de PCR consiste em desnaturação do DNA, hibridação e polimerização. Primeiramente, ocorre a desnaturação do DNA, por aquecimento, que separa a dupla-hélice em duas fitas individuais, a seguir ocorre a hibridação na região complementar do iniciador com o gene alvo escolhido, e se isso ocorrer, 
a polimerase irá colocando nucleotídeos complementares à sequência alvo, este processo se repete com crescimento linear. O iniciador é uma seqüência sintética, de fita única, com 20 a 30 bases de uma região alvo do DNA do microrganismo que dá especificidade à reação. Dessa forma, produz-se uma grande quantidade de DNA copiado da região alvo (amplificação). Com isso, torna uma quantidade pequena do DNA para uma analiticamente mensurável. Indica-se, então, a presença do microrganismo alvo na amostra pesquisada. É bastante útil para determinar prevalências de espécies, pois apenas indica a presença ou não do microrganismo. É uma técnica altamente sensível, mas bastante crítica, com alguns aspectos que podem prejudicar a metodologia, como o tamanho do iniciador, a temperatura de hibridação e a contaminação externa. Para tentar minimizar esses problemas, outras modificações da PCR foram desenvolvidas. Dentre elas encontram-se a PCR múltipla, que amplifica diversas regiões alvo, colocando-se todos os iniciadores necessários em uma única reação (Dangtuan; Rudney, 1996; García et al., 1998; Henegariu et al., 1997), e a PCR quantitativa que permite determinar, por comparação, todos os fragmentos de DNA gerados usando controles de quantidades conhecidas (Doungudomdacha et al., 2001).

\subsubsection{PCR quantitativa (PCR em tempo real, qPCR)}

A PCR em tempo real (qPCR) aumentou a aplicação como método diagnóstico, por ser mais rápido, sensível e mais fácil de ser reproduzido, em comparação ao PCR convencional, além de diminuir a possibilidade de contaminação da amostra a ser estudada. Esse método é mais rápido por possuir ciclos de temperaturas mais curtos, e também devido ao uso de detectores fluorescentes, que permitem uma rápida visualização das réplicas de fragmentos de DNA. Diferente da PCR convencional, a qPCR exclui a necessidade de diluir a réplica do fragmento para sua detecção, pois é capaz de detectar um alvo na presença de muitos outros fragmentos durante o processo de duplicação. Outra 
vantagem sobre a PCR convencional é que a qPCR é capaz de detectar mutações do genoma, graças aos seus reagentes químicos.

As aplicações da qPCR em microbiologia são bastante amplas. No diagnóstico de vírus, essa técnica tem um importante papel, pois já conseguiu identificar muitas espécies e diagnosticar muitas doenças virais e foi capaz de identificar as quantidades de vírus em diferentes momentos da infecção, podendo então compreender o papel desses microrganismos como patógenos.

Muitas bactérias conhecidas, e outras exóticas, puderam ser detectadas pela $\mathrm{qPCR}$, assim como aquelas patógenas da doença periodontal. Ultimamente muitos trabalhos comprovam a eficiência do qPCR como método de diagnóstico para diferenciar bactérias específicas da doença periodontal.

Jervøe-Storm et al. (2005), compararam a qPCR com a técnica de cultura na detecção de $A$. actinomycetemcomitans, $P$. gingivalis, $P$. intermedia, e $T$. forsythia. Coletaram amostras de 78 bolsas gengivais, com cones de papel estéreis. Cada amostra foi dividida em dois: uma parte foi cultivada e outra analisada pela qPCR. Concluíram que a qPCR detectou muito mais patógenos do que cultura.

Morillo et al. (2003), desenvolveram qPCR baseada em SYBR Green (um corante) para identificar $A$. actinomycetemcomitans e $P$. gingivalis. Porém, segundo Kuboniwa et al. (2004), qPCR mais confiável para distinguir bactérias é a que utiliza sondas. Ela é capaz de distinguir bactérias muito similares, como $P$. intermedia e $P$. nigrescens, ou como $A$. actinomycetemcimitans e Haemophilus actinomycetemcomitans. Em seu trabalho, propôs comprovar a eficácia de TaqMan ${ }^{\circledR}$ qPCR para a detecção de seis bactérias: $A$. actinomycetemcomitans, $P$. gingivalis, P. intermedia, T. forsythia, e T. denticola. Concluiu que o método estudado é eficiente para a detecção dos seis microrganismos citados.

Yoshida et al. (2004) estudaram a relação de números relativos e absolutos de Treponema denticola e a progressão da doença periodontal. No total, 53 amostras foram coletadas de bolsas periodontais profundas através de pontas de papel estéreis, e depois submetidas a qPCR. Concluíram que a quantidade de $T$. denticola é proporcional ao tamanho da bolsa periodontal. 
A quantificação de DNA pela PCR apresenta-se como uma técnica potencial no diagnóstico microbiológico, uma vez que ela permite não apenas a detecção de microrganismos específicos, mas, também, sua quantificação. Algumas metodologias estão sendo desenvolvidas de modo que se alcance resultados mais confiáveis e reprodutíveis (Morillo et al., 2004; Nonnenmacher et al., 2004; Sanz et al., 2004).

Lau et al. (2004), mostrou uma concordância entre PCR quantitativa e cultura na detecção de Actinobacillus actinomycetemcomitans, Porphyromonas gingivalis e Tannerella forsythensis, mostrando ser possível quantificar as espécies presentes subgengivalmente, com sensibilidade e especificidade maiores que da técnica de cultura, concluindo que as altas sensibilidade e especificidade da PCR quantitativa justificam seu uso tanto epidemiologicamente quanto como adjunto ao diagnóstico clínico de indivíduos com periodontite. Mas é uma técnica com custo acessível e seu custo/benefício como adjunto no diagnóstico microbiológico clínico deve ser avaliado. Estudos clínicos ainda precisam ser conduzidos de forma que esclareça sua utilidade diagnóstica (Sanz et al., 2004). Estudos recentes estão avaliando a possibilidade da utilização da PCR quantitativa para testes de susceptibilidade antimicrobiana (Rolain et al., 2004).

As PCR são as mais sensíveis dentre as técnicas apresentadas. No entanto, não se sabe até que ponto a presença de quantidades mínimas de microrganismos no biofilme poderia contribuir no mecanismo patogênico da doença periodontal. 


\section{PROPOSIÇÕES}

Avaliar as alterações clínicas e microbiológicas, pela PCR em tempo real, resultantes do tratamento periodontal não-cirúrgico associado ao uso de amoxicilina e de metronidazol, em indivíduos portadores de periodontite agressiva. Validar a qPCR para quantificação bacteriana de amostras periodontais. 


\section{MATERIAL E MÉTODOS}

\subsection{DELINEAMENTO DO ESTUDO E CASUÍSTICA}

Os indivíduos que participaram deste estudo leram, entenderam e assinaram o termo de consentimento livre-esclarecido aprovado pela Comissão de Ética em Pesquisa da Faculdade de Odontologia da USP (Protocolo 170/05) (anexos A e B).

Foram selecionados indivíduos de ambos os sexos, que obedeceram aos seguintes critérios de inclusão: 1) diagnóstico clínico de periodontite agressiva segundo os critérios da Academia Americana de Periodontia (AAP, 1999): história médica não-significativa; rápida perda de inserção e destruição óssea; concentração familiar dos casos; 2) idade entre 13 e 35 anos, 3) presença de pelo menos 20 dentes na cavidade bucal, 4) consentimento em participar do estudo e assinar o termo de consentimento livre e esclarecido (anexo A).

Os critérios de exclusão foram os seguintes: 1) tratamento periodontal nos últimos 6 meses, 2) uso de antibióticos nos últimos 6 meses, 3) histórico de sensibilidade ao(s) antimicrobiano(s) indicado(s), 4) gravidez ou lactação, 5) doença sistêmica que modifique a doença periodontal, 6) necessidade de antibioticoterapia profilática.

\subsection{OBTENÇÃO DOS PARÂMETROS CLÍNICOS:}

A seleção dos indivíduos foi realizada através de anamnese (anexo C), exame clínico (anexo D) e exame radiográfico (jogo completo com 14 radiografias periapicais), a fim de se determinar o diagnóstico da doença periodontal. 
O exame clínico consistiu no preenchimento de uma ficha periodontal (periograma) onde foram registrados, com sonda milimetrada $^{1}$, por 2 examinadores calibrados, em seis sítios por dente, os seguintes parâmetros clínicos: distância da margem gengival à junção esmalte-cemento (MG-JEC); profundidade clínica de sondagem (PCS), nível clínico de inserção $(\mathrm{NCl})$, sangramento à sondagem (SS) e dentes ausentes. Também foi registrado o Índice de Placa (IP) (O'Leary et al., 1972), através da visualização de biofilme dental corado por verde de malaquita. As calibrações intra e inter-examinadores foram realizadas previamente ao estudo, para verificar a reprodutibilidade das medidas. As concordâncias, avaliadas pelo coeficiente de correlação intra-classe (ICC), foram altas para $\mathrm{NCl}$ (intra-examinador: ICC = 0,91, IC 95\% 0,88-0,93; e interexaminadores: ICC $=0,80$, IC 95\% 0,727-0,855) e para PCS (intra-examinador: ICC $=0,95$, IC 95\% 0,93-0,96; e inter-examinadores: ICC = 0,78, IC 95\% 0,709$0,845)$.

\subsection{COLETA DAS AMOSTRAS}

Para cada paciente foram coletadas quatro amostras de biofilme subgengival, em quatro sítios distintos, sendo estes os sítios mais profundos de cada hemiarco, com preferência para $1^{\text {os }}$. molares e incisivos. Inicialmente, a área a qual pertencia o sítio selecionado foi isolada com roletes de algodão e seca com jatos de ar. A seguir, o biofilme supragengival dos sítios selecionados foi removido com bolinhas de algodão estéreis e curetas periodontais ${ }^{2}$. As amostras de biofilme subgengival foram obtidas através da introdução de pontas de papel absorvente estéril $^{3}$, no interior da bolsa periodontal de cada sítio, permanecendo por 20 segundos (Hartroth et al., 1999) no interior da bolsa. Depois, as 4 pontas foram

\footnotetext{
${ }^{1}$ PCPUNC 15, Hu-Friedy, Chicago, IL, USA

${ }^{2}$ Curetas gracey 5-6; 11-12; 13-14, Hu-Friedy, Chicago, IL, USA

${ }^{3}$ Tanari \#30, SP, Brasil
} 
transferidas para o interior de um mesmo tubo ${ }^{4}$ de $1,5 \mathrm{ml}$, estéril. Os tubos contendo as amostras foram estocados à $-20^{\circ} \mathrm{C}$.

\subsection{PROCEDIMENTOS CLÍNICOS}

Após a coleta dos dados iniciais, os indivíduos receberam tratamento periodontal não-cirúrgico (procedimentos básicos) que consistiu em orientação de higiene bucal com escova e fio dental e outros métodos de controle mecânico de biofilme dental, pelo paciente, que fossem necessários; raspagem e alisamento coronário e radicular com ultrassom ${ }^{5}$ e curetas periodontais; procedimentos odontológicos emergenciais como restaurações e próteses provisórias e exodontias.

Após 45 dias do término dos procedimentos básicos, um novo periograma foi realizado e uma nova coleta de biofilme subgengival dos sítios mais profundos de cada hemiarco, totalizando 4 sítios. Neste momento, os indivíduos passaram por desbridamento, com ultrassom, supra e subgengival para a desorganização do biofilme, a fim de possibilitar melhor ação da medicação sobre os microrganismos, e foram medicados com a associação de metronidazol (400mg) e amoxicilina (500mg), de 8 em 8 horas, por 7 dias.

Nova coleta de biofilme subgengival foi realizada 1 mês após o uso dos antimicrobianos. Novos periogramas foram realizados nos momentos de 1, 3 e 6 meses após o tratamento com os antibióticos, assim como controle profissional de biofilme dental.

As seguintes bactérias foram analisadas pela $\mathrm{PCR}$ em tempo real: Aggregatibacter actinomycetemcomitans (A. a.), Porphyromonas gingivalis (P. g.), Tannerella forsythia (T. f.), Treponema denticola (T. d.) e Dialister pneumosintes (D. p.).

\footnotetext{
${ }^{4}$ Axygen Scientific, CA, USA

${ }^{5}$ Mini-piezon EMS Electro Medical Systems, Nyon, Switzerland.
} 


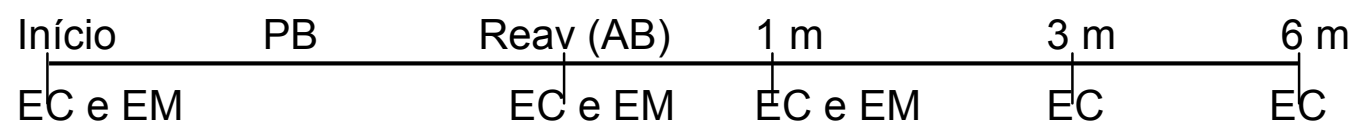

Figura 4.1 - Cronograma do estudo : $E C$ = exame clínico, $E M=$ exame microbiológico, $\mathrm{PB}=$ procedimentos básicos, $A B=$ antibioticoterapia, Reav $=$ reavaliação.

4.5 REALIZAÇÃO DA REAÇÃO EM CADEIA PELA POLIMERASE EM TEMPO REAL (qPCR)

\subsubsection{Procedimento para obtenção de controle interno para quantificação}

\subsubsection{Extração de DNA das cepas bacterianas}

O conjunto de reagentes da QIAamp DNA mini $\mathrm{kit}^{6}$ foi utilizado para a extração do DNA das células bacterianas partindo-se de 100ul de uma suspensão contendo aproximadamente $10^{6}$ células $/ \mathrm{ml}$. O protocolo utilizado estava de acordo com as orientações do fabricante. Foi adicionado aos microtubos contendo a suspensão de células bacterianas, $20 \mathrm{ul}$ de proteinase $\mathrm{K}$ e $200 \mathrm{ul}$ de solução tampão (buffer $A L$ ), presentes no kit de extração. Os microtubos foram, então, encubados a $56^{\circ} \mathrm{C}$, por $10 \mathrm{~min}$. Em seguida, adicionou-se $300 \mathrm{ul}$ de etanol e iniciou-se um ciclo de repetidas centrifugações e adições de soluções tampão, conforme o protocolo fornecido pelo fabricante. Ao final, o DNA extraído ficou eluído em solução tampão.

${ }^{6}$ Qiagen, Hilden, Alemanha 
A quantidade e a pureza do DNA genômico extraído das amostras foram determinadas por densidade óptica em espectrofotômetro ${ }^{7}$ com leitura em 260/280nm, utilizando-se uma alíquota da solução de cada amostra de DNA. A absorbância de 260nm equivale à quantidade de DNA e a de 280nm a de proteínas. A pureza dos extratos de DNA foi obtida pela razão de absorbância 260nm/280nm. O valor considerado ideal foi de 1,8 a 2,0.

4.5.1.2 PCR para amplificação de fragmentos de DNA das bactérias A. a., P. g., T. d., T. f. e D. p., para clonagem

As cepas bacterianas provenientes da American Type Culture Collection (ATCC) (tabela 4.1), foram cultivadas no laboratório de microbiologia do Instituto de Ciências Biomédicas da Universidade de São Paulo. Os fragmentos de DNA correspondentes a regiões altamente conservadas do gene $16 S$ rRNA das bactérias A. a., P. g., T. d., T. f. e D. p. foram amplificados através da PCR para serem utilizados na clonagem.

Tabela 4.1 - Cepas Bacterianas

\begin{tabular}{ll}
\hline Bactéria & Cepa \\
\hline Porphyromonas gingivalis & ATCC 49417 \\
\hline Treponema denticola & ATCC 33521 \\
\hline Tannerella forsythia & ATCC 43037 \\
\hline Aggregatibacter actinomycetemcomitans & ATCC 29522 \\
\hline Dialister pneumosintes & ATCC 33048 \\
\hline
\end{tabular}

Os iniciadores foram desenhados baseados nas regiões espécieespecíficas altamente conservadas do gene 16S rRNA, através do uso do

\footnotetext{
${ }^{7}$ NanoDrop® ND-1000 UV-Vis, NanoDrop Technologies, Wilmington, EUA
} 
programa Primer Express ${ }^{\mathrm{TM}} 8$ e sintetizados (tabela 4.2). As especificidades dos iniciadores foram confirmadas empregando-se o programa BLAST do National Center for Biotechnology Information Sever (http://ncbi.nlm.nih.gov/blast/).

Tabela 4.2 - Iniciadores utilizados na reação da PCR

\begin{tabular}{|c|c|c|}
\hline Iniciadores & Sequência (5'- 3') & No. de acesso \\
\hline \multicolumn{3}{|l|}{$P g$} \\
\hline senso & ACCTTACCCGGGATTGAAATG & AF118634 \\
\hline anti-senso & CAACCATGCAGCACCTACATAGAA & \\
\hline \multicolumn{3}{|l|}{$T f$} \\
\hline senso & AGCGATGGTAGCAATACCTGTC & AM039448 \\
\hline anti-senso & TTCGCCGGGTTATCCCTC & \\
\hline \multicolumn{3}{|l|}{$T d$} \\
\hline senso & CCGAATGTGCTCATTTACATAAAGGT & AJ277354 \\
\hline anti-senso & GATACCCATCGTTGCCTTGGT & \\
\hline \multicolumn{3}{|l|}{$D p$} \\
\hline senso & TGGAGCGGACCTCATAAACG & X82500 \\
\hline anti-senso & TCATGCAGGCGAGTTGCA & \\
\hline \multicolumn{3}{|l|}{$A a$} \\
\hline senso & AGCAGCCGCGGTAATACG & M75039 \\
\hline anti-senso & GCCCTTTACGCCCAGTTATTC & \\
\hline
\end{tabular}

Para o ensaio da PCR, as reações foram realizadas utilizando-se $2 \mu \mathrm{l}$ de DNA das cepas bacterianas, iniciadores senso e anti-senso 200 nM (Prodimol Biotecnologia, Belo Horizonte, MG, Brasil), dNTP 800 nM (Amersham Biosciences, Piscataway/NJ, EUA), DNA polimerase $1 U$ (Biotools, Madri, Espanha), tampão de PCR 1x (Tris-HCl 75 mM, pH 9,0; KCl 50 mM; (NH4)2 $\mathrm{SO}_{4} 20$ mM), $\mathrm{MgCl}_{2} 2 \mathrm{nM}$ e água deionizada estéril para um volume final de $50 \mu$ l.

A PCR foi realizada no termociclador Mastercycler ${ }^{\circledR}$ Gradient $^{9}$, utilizando o seguinte programa: desnaturação inicial a $96^{\circ} \mathrm{C}$ por $3 \mathrm{~min}$; seguida de 35 ciclos de desnaturação a $94^{\circ} \mathrm{C}$ por $1 \mathrm{~min}, 60^{\circ} \mathrm{C}$ por 1 min para hibridização e $72^{\circ} \mathrm{C}$ por 1 min. para extensão, e etapa de extensão final de $72^{\circ} \mathrm{C}$ por $10 \mathrm{~min}$. Os produtos

\footnotetext{
${ }^{8}$ Applied Biosystems, Foster City, CA

${ }^{9}$ Eppendorf AG, Hamburg, Alemanha
} 
gerados pela PCR foram analisados por eletroforese em gel de agarose $1 \% \mathrm{em}$ TBE (Sambrook; Russel, 2001). As bandas foram visualizadas sob luz ultravioleta (UV), após coloração do gel com brometo de etídio $(0,5 \mathrm{mg} / \mathrm{mL})$ e fotodocumentadas em sistema de captura de imagem Chemilmager $^{\mathrm{TM}} 4400^{10}$.

\subsubsection{Purificação dos produtos da PCR para clonagem}

A purificação foi realizada recortando-se os fragmentos identificados no gel de agarose utilizando o sistema comercial GFX Genomic DNA kit ${ }^{11}$ seguindo as recomendações do fabricante.

4.5.1.4 Reação de ligação dos fragmentos dos genes obtidos pela PCR com o plasmídeo

O fragmento de gene amplificado pela PCR dos agentes infecciosos $A$. a., P. g., T. d., T. f. e D. p. e o plasmídeo pGEM ${ }^{\circledR}-T$ Easy Vector ${ }^{12}$ foram submetidos à reação de ligação (clonagem) conforme as orientações do fabricante. $O$ produto desta reação foi utilizado para transformação de E. coli DH-5a. Os plasmídeos recombinantes foram denominados pGem::16S rRNA Aa, pGem::16S rRNA Pg, pGem::16S rRNA Td, pGem::16S rRNA Tf e pGem::16S rRNA Dp.

4.5.1.5 Preparação das bactérias competentes

\footnotetext{
${ }^{10}$ Alpha Innotech Corporation, San Leandro, CA, EUA

${ }^{11} \mathrm{GE}$ Healthcare

${ }^{12}$ pGEM®-T Easy Vector System I, Promega
} 
A partir de uma colônia isolada de bactéria $E$. coli cepa $\mathrm{DH}-5$ a, foi realizado repique para a expansão, utilizando meio líquido de cultura LB sem antibiótico e incubando-se, sob agitação, a $37^{\circ} \mathrm{C}$, até a obtenção de uma densidade óptica (DO) de $600 \mathrm{~nm}$. A suspensão resultante foi centrifugada, o sobrenadante desprezado e as células decantadas. Em seguida, o material foi tratado com solução de $\mathrm{CaCl}_{2} 50 \mathrm{mM}$ por 30 minutos e centrifugado a $4000 \mathrm{~g}$ durante 5 minutos. As células foram novamente ressuspensas em solução de $\mathrm{CaCl}_{2} 50 \mathrm{mM} \mathrm{e}$ $5 \%$ de DMSO, e conservadas a $-70^{\circ} \mathrm{C}$ até o momento da transformação (Sambrook; Russel, 2001).

\subsubsection{Transformação da E. coli com o plasmídeo recombinante}

Para a transformação foram utilizados $50 \mu \mathrm{L}$ de suspensão de bactérias $E$. coli (células competentes) e $2 \mu \mathrm{L}$ de produto da reação de ligação (plasmídeo recombinante). A mistura foi homogeneizada e incubada por 20 minutos em banho de gelo, por 50 segundos a $42^{\circ} \mathrm{C}$ sem agitação e, novamente, em banho de gelo por mais 2 minutos. Foi adicionado $950 \mu \mathrm{l}$ de meio SOC e incubado a $37^{\circ} \mathrm{C}$ por 90 minutos com agitação. $O$ produto de transformação ( $E$. coli recombinante) foi semeado em meio de cultura LB ágar contendo ampicilina $(100 \mu \mathrm{g} / \mathrm{ml})$ com incubação a $37^{\circ} \mathrm{C}$ por uma noite (Sambrook; Russel, 2001).

\subsubsection{Extração do DNA plasmidial}

Partindo-se de uma colônia de E. coli isolada e carreadora do plasmídeo pGEM®-T Easy Vector contendo o inserto, foi realizada a incubação em $5 \mathrm{ml}$ de meio de cultura LB líquido com antibiótico $(100 \mu \mathrm{g} / \mathrm{ml})$ por uma noite a $37^{\circ} \mathrm{C}$, com agitação. As colônias foram centrifugadas a $5000 \mathrm{~g}$ por 5 minutos, $4 \mathrm{ml}$ do sobrenadante foram removidos e o restante resuspenso e transferido para um 
microtubo de $1,5 \mathrm{ml}$ estéril. O microtubo foi centrifugado a $12000 \mathrm{~g}$ por 5 minutos e o sobrenadante removido. O sedimento foi utilizado para extração dos plasmídeos, de acordo com o protocolo de orientação do kit de extração GFX Micro Plasmid Prep $\mathrm{Kit}^{13}$. O DNA plasmidial foi coletado no microtubo e mantido a $-20^{\circ} \mathrm{C}$.

Aproximadamente $5 \mu \mathrm{l}$ da solução contendo o plasmídeo recombinante foram submetidas à restrição enzimática e analisadas por eletroforese em gel de agarose a 1\%, para confirmação da presença do fragmento clonado (Sambrook; Russel, 2001).

4.5.1.8 Análise do controle exógeno para quantificação do número de cópias do genoma bacteriano

Um total de $1 \mu \mathrm{l}$ da solução contendo o plasmídeo recombinante foi quantificado por espectrofotometria em UV (aparelho: NanoDrop® ND-1000 UVVis, NanoDrop Technologies, Wilmington, EUA).

A partir da massa molecular do plasmídeo recombinante, obtida através do programa Oligo Calculator (http://www.pitt.edu/ rsup/OligoCalc.html), e de sua quantificação por espectrofotometria, foram determinados os números de cópias do genoma de cada bactéria-alvo através da fórmula:

$(Y \times 6,02 \times 104) / Z$

onde $\mathrm{Y}$ é o valor da quantificação por espectrofotometria e $Z$ é o valor da massa molecular do plasmídeo recombinante (Skipper et al., 2006).

Diluições seriadas $\left(10^{1}\right.$ a $\left.10^{10}\right)$ de concentrações conhecidas foram realizadas para cada um dos plasmídeos recombinantes. Essas diluições foram processadas pela PCR em tempo real para obtenção de curvas de quantificação que serviram como controle interno para a quantificação das bactérias.

\footnotetext{
${ }^{13}$ Amersham Biosciences, Piscataway/NJ, EUA
} 
Uma vez determinados os limites de quantificação, todas as amostras biológicas foram amplificadas pela PCR em tempo real juntamente com as curvas padrões correspondentes a cada espécie bacteriana.

\subsubsection{Preparo das amostras biológicas para extração de DNA}

O conjunto de reagentes da QIAamp DNA mini $\mathrm{kit}^{14}$ foi utilizado para a extração do DNA presente nas amostras, seguindo as orientações do fabricante. No entanto, estabelecemos um preparo inicial das amostras, a fim de se garantir a qualidade da extração do material genético presente nas pontas de papel absorvente utilizadas para a coleta do material subgengival. Esse preparo consistiu em se adicionar 200ul de solução tampão (PBS - phosphate-buffer saline) aos cones de papel e manutenção dos microtubos sob agitação por 12 horas. Após esse preparo inicial, foram adicionados aos microtubos 20ul de proteinase $\mathrm{K}$ e 200ul de solução tampão (buffer $\mathrm{AL}$ ), presentes no kit de extração. Os microtubos foram então encubados a $56^{\circ} \mathrm{C}$, por $10 \mathrm{~min}$. Em seguida, adicionou-se 300ul de etanol e iniciou-se um ciclo de repetidas centrifugações e adições de soluções tampão, conforme o protocolo fornecido pelo fabricante. Ao final, o DNA extraído ficou eluído em solução tampão.A quantidade e a pureza do DNA genômico extraído das amostras foram determinadas por densidade óptica em espectrofotômetro com leitura em 260/280nm, utilizando-se uma alíquota da solução de cada amostra de DNA. A absorbância de $260 \mathrm{~nm}$ equivale à quantidade de DNA e a de $280 \mathrm{~nm}$ a de proteínas. A pureza dos extratos de DNA foi obtida pela razão de absorbância $260 \mathrm{~nm} / 280 \mathrm{~nm}$. O valor considerado ideal foi de 1,8 a 2,0 .

\footnotetext{
${ }^{14}$ Qiagen, Hilden, Alemanha
} 


\subsubsection{Reação em cadeia pela polimerase em tempo real (PCR em tempo real, qPCR):}

A identificação e a quantificação absoluta das bactérias $A$. a., P. g., T. d., T. f. e D. p. nas amostras clínicas foram realizadas através da PCR em tempo real, utilizando-se o sistema de amplificação com sondas TaqMan® e detecção pelo equipamento ABI PRISM 7500 Sequence Detection System ${ }^{15}$. A PCR em tempo real foi realizada utilizando uma solução de $25 \mu \mathrm{L}$ contendo $0,5 \mu \mathrm{L}$ de $200 \mathrm{nmol}$ de cada oligonucleotídeo iniciador, $0,5 \mu \mathrm{L}$ de $200 \mathrm{nmol}$ de sonda TaqMan $\circledast, 12,5 \mu \mathrm{L}$ de Taqman $®$ Universal PCR Master Mix ${ }^{16}, 9 \mu \mathrm{L}$ de água estéril e $2 \mu \mathrm{L}$ de solução de DNA. A reação de amplificação foi realizada com as seguintes etapas: temperatura de desnaturação inicial de $95^{\circ} \mathrm{C}$ por 10 minutos e amplificação por 40 ciclos a $95^{\circ} \mathrm{C}$ por 10 segundos e $60^{\circ} \mathrm{C}$ por 1 minuto.

As sondas TaqMan ${ }^{\circledR}$ para cada uma das bactérias investigadas também foram desenhadas baseadas nas regiões espécie-específicas altamente conservadas do gene 16S rRNA, com o auxílio do programa Primer Express ${ }^{\text {TM }}{ }^{17}$, e as especificidades foram confirmadas empregando-se o programa BLAST (Basic Local Alignment Search Tool) ${ }^{18}$.

As seqüências dos iniciadores estão listadas na tabela 4.2 e as sequências das sondas, com os respectivos marcadores nas extremidades $5^{\prime}$ (repórter) e 3 (quencher), estão listadas na tabela 4.3.

\footnotetext{
${ }^{15}$ Applied Biosystems, Foster City, CA

${ }^{16}$ Applied Biosystems, Foster City, CA

${ }^{17}$ Applied Biosystems, Foster City, CA, EUA

${ }^{18}$ National Center for Biotechnology Information Sever (http://ncbi.nlm.nih.gov/blast/
} 
Tabela 4.3 - Sondas TaqMan® utilizadas na PCR em tempo real

\begin{tabular}{ll}
\hline Bactérias & Sonda TaqMan® (5'-3') \\
\hline P. g. & 5'-/5HEX/ATGACTGATGGTGAAAACCGTCTTCCCTTC/3IABIkFQ/-3' \\
\hline T. d. & 5'-/5CY5/ATGGGCCCGCGTCCCATTAGC/3IAbRQSp/-3' \\
\hline T. f. & 5'-/6FAM/CACGGGTGAGTAACG/MGBNFQ/-3' \\
\hline
\end{tabular}

A. a. 5'-/6FAM/TGCGAGCGTTAATC/MGBNFQ/-3'

D. p. 5'-/6FAM/CCCAGTTCAGATTGC/MGBNFQ/-3'

HEX: hexachloro 6-carboxy-fluorescein; 3IABIkFQ: lowa black FQ ${ }^{\mathrm{IM}} ; \mathrm{CY}^{\mathrm{IM}}$ : Cyanine 5 ; 3IAbRQSp: lowa black $R Q^{T M} ; F M^{T M}$ : fluoróforo repórter; $M G B^{T M}$ : Minor Groove Binder; NFQ: non-fluorescent quencher

Diluições seriadas de quantidades conhecidas de cópias $\left(10^{1}\right.$ a $\left.10^{10}\right)$ de plasmídeos recombinantes foram processadas pela PCR em tempo real, utilizando-se os iniciadores e as sondas descritas para cada microrganismo, e curvas-padrão foram geradas para cada bactéria-alvo (figura 4.2). O limite mínimo de quantificação para A. a. e $T$. d. foi de 1000 cópias, enquanto que para P. g., T. f. e $D$. p. esse limite foi de 100 cópias. Um limite máximo de quantificação de $10^{9}$ cópias foi estabelecido para todas as bactérias.

Uma vez determinados os limites de quantificação, as amostras clínicas foram processadas juntamente com os controles, em triplicatas, e os valores médios foram utilizados para o cálculo das quantidades de bactérias. Um total de aproximadamente 700 reações foram realizadas, todas respeitando a eficiência da reação de amplificação para a curva-padrão entre 110 a 93\% (slope $=-3,10$ a 3,50 ), sendo que a maioria das reações apresentou uma eficiência considerada entre 95 e 100\% (slope $=-3,30$ ).

As diluições das cópias dos plasmídeos serviram como controle positivo para a reação de amplificação e como controle negativo substituiu-se o DNA pela mesma quantidade de água estéril, a fim de se checar possíveis contaminações. 


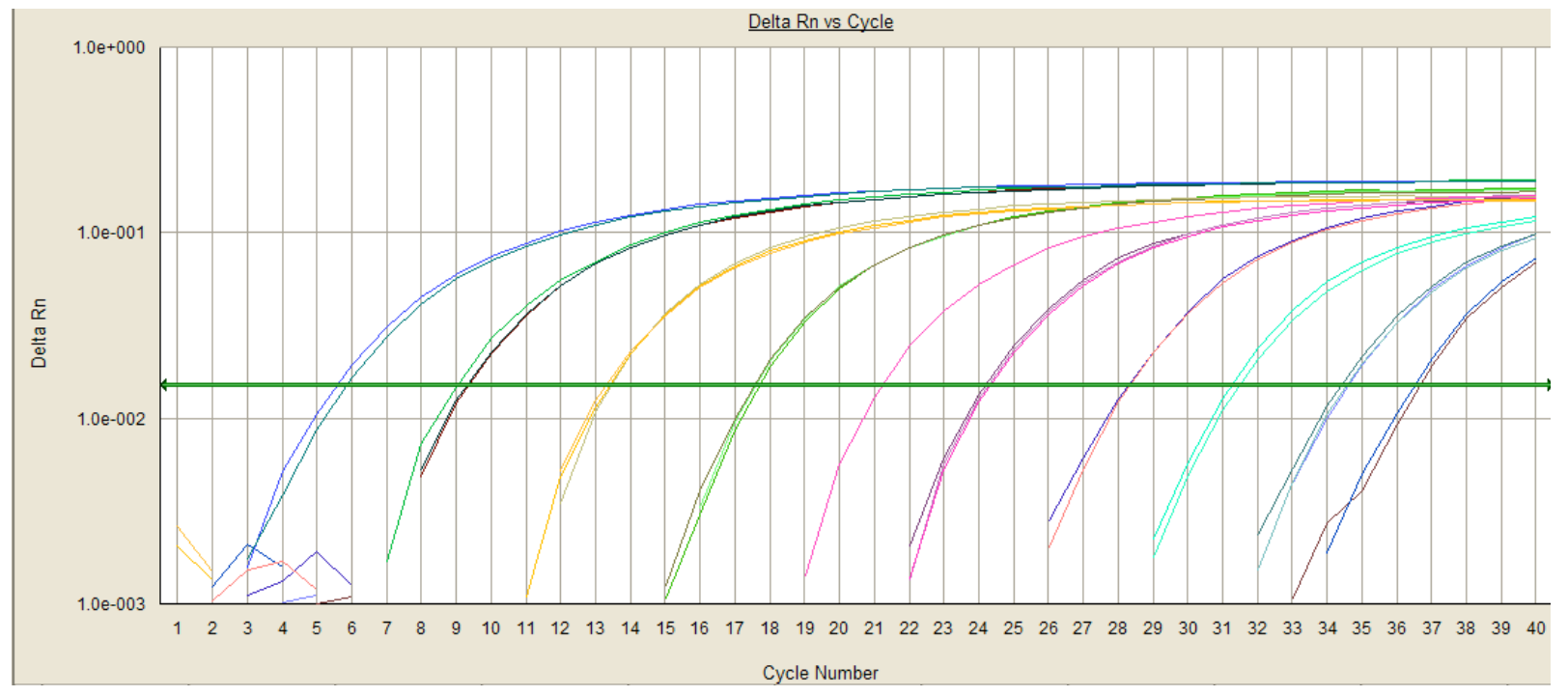

Figura 4.2 - Curvas de quantificação da bactéria Porphyromonas gingivalis

\subsection{ANÁLISE ESTATÍSTICA}

Análise de variância de medidas repetidas foi realizada para verificar alterações no tempo em relação aos parâmetros clínicos e microbiológicos. As mudanças no tempo em relação à presença/ausência das bactérias foi avaliada pelo teste de McNemar. Todos os testes foram realizados com um alfa de $5 \%$. 


\section{RESULTADOS}

No total, foram triados 41 pacientes com periodontite agressiva. Destes, 5 não foram incluídos no estudo devido aos fatores de exclusão (alérgicos à amoxicilina); 8 não concordaram em realizar o tratamento periodontal na FOUSP. Assim, 28 indivíduos iniciaram o estudo. Destes, 4 utilizaram antibióticos por outros motivos durante o tratamento periodontal e foram excluídos; 1 paciente engravidou; 8 abandonaram o tratamento ou não retornaram corretamente às consultas. Os 15 sujeitos incluídos no estudo completaram o tratamento periodontal não-cirúrgico e fizeram o uso dos antibióticos corretamente. Não foram relatadas reações adversas ao uso dos antibióticos. Três indivíduos não retornaram para as avaliações clínicas de 3 e 6 meses após o uso dos antimicrobianos.

Houve maior presença de mulheres. A média de idade dos indivíduos foi 27,73 anos e em média apresentaram 28 dentes na cavidade bucal (tabela 5.1).

Tabela 5.1 - Características demográficas

\begin{tabular}{ll}
\hline Variáveis & $\mathrm{N}=15$ \\
\hline Idade (média $\pm \mathrm{DP})$ & $27,73 \pm 5,84$ \\
\hline $\mathrm{N}$ mulheres $(\%)$ & $11(73,3)$ \\
\hline $\mathrm{N}$ dentes (média $\pm \mathrm{DP})$ & $28 \pm 1,77$ \\
\hline
\end{tabular}

A análise estatística demonstrou a presença de uma redução significativa dos parâmetros clínicos SS e PCS em todos os momentos do estudo em relação ao início (tabela 5.2). Houve aumento significativo da distância da margem gengival em relação ao limite esmalte-cemento (LEC-MG) aos 3 e 6 meses após o uso do antimicrobiano em relação ao início, e redução estatisticamente significante do IP 1 mês após o uso dos antimicrobianos e essa redução se manteve até o final do estudo. A média de redução da PCS foi de mais de $1,25 \mathrm{~mm}(p<0,0001)$ e a de retração da margem gengival foi de $0,66 \mathrm{~mm}(p<0,05)$ após 6 meses do 
tratamento. Já a média de redução de $\mathrm{NCl}$ foi de $0,55 \mathrm{~mm}$, mas este valor não foi estatisticamente significante.

Tabela 5.2 - Parâmetros clínicos dos sujeitos de pesquisa no início, reavaliação, 1, 3 e 6 meses após antibiótico

\begin{tabular}{|c|c|c|c|c|c|c|c|c|c|}
\hline Variável & $\begin{array}{l}\text { Início } \\
\text { (média } \\
\pm D P \text { ) }\end{array}$ & $\begin{array}{l}\text { Reavaliação } \\
\text { (média } \pm \text { DP) }\end{array}$ & $\begin{array}{c}p \text { valor } \\
\text { início x } \\
\text { reav. }\end{array}$ & $\begin{array}{l}1 \text { mês } \\
\text { (média } \\
\pm \mathrm{DP} \text { ) }\end{array}$ & $\begin{array}{c}p \text { valor } \\
\text { início x } 1 \\
\text { mês }\end{array}$ & $\begin{array}{c}3 \\
\text { meses } \\
\text { (média } \\
\pm D P \text { ) }\end{array}$ & $\begin{array}{c}p \text { valor } \\
\text { início x } 3 \\
\text { meses }\end{array}$ & $\begin{array}{c}6 \\
\text { meses } \\
\text { (média } \\
\pm D P \text { ) }\end{array}$ & $\begin{array}{c}p \text { valor } \\
\text { início x } 6 \\
\text { meses }\end{array}$ \\
\hline $\begin{array}{l}\text { LEC-MG } \\
\qquad(\mathrm{mm})\end{array}$ & $\begin{array}{c}0,35 \pm \\
0,41\end{array}$ & $0,48 \pm 0,50$ & 0,98 & $\begin{array}{c}0,66 \pm \\
0,63\end{array}$ & 0,71 & $\begin{array}{c}0,94 \pm \\
0,90\end{array}$ & $0,043^{*}$ & $\begin{array}{c}1,01 \pm \\
0,92\end{array}$ & $0,039^{*}$ \\
\hline $\begin{array}{l}\text { PCS } \\
(\mathrm{mm})\end{array}$ & $\begin{array}{c}3,69 \pm \\
0,94\end{array}$ & $2,97 \pm 0,63$ & $0,031^{*}$ & $\begin{array}{c}2,67 \pm \\
0,40\end{array}$ & $0,01^{*}$ & $\begin{array}{c}2,44 \pm \\
0,60\end{array}$ & $<0,0001^{*}$ & $\begin{array}{c}2,44 \pm \\
0,61\end{array}$ & $<0,0001^{*}$ \\
\hline $\begin{array}{c}\mathrm{NCl} \\
(\mathrm{mm})\end{array}$ & $\begin{array}{c}3,82 \pm \\
1,07\end{array}$ & $3,23 \pm 1,05$ & 0,54 & $\begin{array}{c}3,13 \pm \\
0,99\end{array}$ & 0,37 & $\begin{array}{c}3,20 \pm \\
1,10\end{array}$ & 0,46 & $\begin{array}{c}3,27 \pm \\
1,07\end{array}$ & 0,81 \\
\hline SS (\%) & $\begin{array}{c}63,18 \pm \\
24,23\end{array}$ & $35,93 \pm 18,26$ & $0,001^{*}$ & $\begin{array}{c}24,71 \\
\pm \\
13,29\end{array}$ & $<0,0001^{*}$ & $\begin{array}{c}21,15 \\
\pm \\
10,00\end{array}$ & $<0,0001^{*}$ & $\begin{array}{c}25,88 \\
\pm \\
16,58\end{array}$ & $<0,0001^{*}$ \\
\hline IP (\%) & $\begin{array}{c}80,19 \pm \\
19,04\end{array}$ & $61,63 \pm 18,89$ & 0,064 & $\begin{array}{c}54,22 \\
\pm \\
18,89\end{array}$ & $0,003^{*}$ & $\begin{array}{c}44,61 \\
\pm \\
15,30\end{array}$ & $<0,0001^{*}$ & $\begin{array}{c}48,07 \\
\pm \\
21,00\end{array}$ & $<0,0001^{*}$ \\
\hline
\end{tabular}

* diferença significativa a $5 \%$

$p$ valor (Newman Keuls) diferença entre os tempos em cada grupo

Os resultados microbiológicos quantitativos (tabela 5.3) corresponderam somente às amostras clínicas que amplificaram dentro dos limites de quantificação estabelecidos pelas curvas padrão de cada bactéria. Os limites mínimos de quantificação para A. a. e para $T$. d. foram de 1000 células, já para P. g., T. f. e D. p., foram de 100 células.

Houve redução estatisticamente significante das quantidades das bactérias T.d. e T.f. 1 mês após o uso dos antimicrobianos com relação ao início (tabela $5.3)$. 
Tabela 5.3 - Número de bactérias $\left(\times 10^{4}\right)$ nos momentos experimentais

\begin{tabular}{cccccc}
\hline Variável & $\begin{array}{c}\text { Início } \\
\text { (média } \pm \mathrm{DP})\end{array}$ & $\begin{array}{c}\text { Reavaliação } \\
(\text { média } \pm \mathrm{DP})\end{array}$ & $\begin{array}{c}p \text { valor } \\
\text { início } \times \text { reav. }\end{array}$ & $\begin{array}{c}\text { 1 mês } \\
(\text { média } \pm \mathrm{DP})\end{array}$ & $\begin{array}{c}p \text { valor } \\
\text { início x } 1 \text { mês }\end{array}$ \\
\hline $\boldsymbol{A a}$ & $103,21 \pm 259,02$ & $1840,15 \pm 6440,38$ & 0,72 & $14,03 \pm 21,99$ & 0,37 \\
\hline $\boldsymbol{P g}$ & $110,02 \pm 214,76$ & $13,33 \pm 23,77$ & 0,57 & $7,53 \pm 8,56$ & 0,07 \\
\hline $\boldsymbol{T d}$ & $177,60 \pm 297,19$ & $1,72 \pm 2,67$ & 0,12 & $0,08 \pm 0,14$ & $0,03^{*}$ \\
\hline $\boldsymbol{T f}$ & $137,28 \pm 184,50$ & $10,62 \pm 20,45$ & 0,07 & $1,51 \pm 3,08$ & $0,04^{*}$ \\
\hline $\boldsymbol{D p}$ & $0,47 \pm 1,04$ & $10,90 \pm 32,96$ & 0,75 & $4,03 \pm 7,09$ & 0,47 \\
\hline
\end{tabular}

${ }^{ \pm}$teste de Newman Keuls; * diferença significativa em relação ao início $(p<0.05)$

As freqüências de P.g. e de T.f. reduziram significativamente 1 mês após o uso dos antibióticos com relação ao início, e, no caso da P.g., também foi estatisticamente significante a diferença de freqüência entre o momento de reavaliação e de 1 mês após o uso dos antibióticos (tabela 5.4). 
Tabela 5.4 - Freqüência das bactérias nos momentos experimentais

\begin{tabular}{ccccccc}
\hline Variável & $\begin{array}{c}\text { Início } \\
\mathrm{n}(\%)\end{array}$ & $\begin{array}{c}\text { Reavaliação } \\
\mathrm{n}(\%)\end{array}$ & $\begin{array}{c}\text { p valor } \\
\text { início } \mathrm{x} \\
\text { reav. }\end{array}$ & $\begin{array}{c}\mathbf{1} \text { mês } \\
\mathrm{n}(\%)\end{array}$ & $\begin{array}{c}\text { p valor } \\
\text { início x 1 mês }\end{array}$ & $\begin{array}{c}p \text { valor } \\
\text { reav. x 1 mês }\end{array}$ \\
\hline $\boldsymbol{A a}$ & $13(86,7 \%)$ & $14(93,3 \%)$ & 1,00 & $15(100,0 \%)$ & - & $0,008^{*}$ \\
\hline $\boldsymbol{P g}$ & $13(86,7 \%)$ & $12(80,0 \%)$ & 1,00 & $04(26,7 \%)$ & $0,004^{*}$ & 0,21 \\
\hline $\boldsymbol{T} \boldsymbol{d}$ & $15(100,0 \%)$ & $14(93,3 \%)$ & - & $10(66,7 \%)$ & - & 0,063 \\
\hline $\boldsymbol{T f}$ & $14(93,3 \%)$ & $13(86,7 \%)$ & 1,00 & $08(53,3 \%)$ & $0,031^{*}$ & 0,125 \\
\hline $\boldsymbol{D p}$ & $15(100,0 \%)$ & $14(93,3 \%)$ & - & $10(66,7 \%)$ & - & \\
\hline
\end{tabular}

p valor: teste de McNemar

* associação significativa a $5 \%$ 


\section{DISCUSSÃO}

Pelo nosso conhecimento, este parece ser o primeiro estudo que avalia os efeitos microbiológicos do tratamento periodontal não-cirúrgico em pacientes com periodontite agressiva através da PCR em tempo real com sonda TaqMan®. Esta análise microbiológica permitiu a avaliação quantitativa, a curto prazo, das mudanças microbiológicas ocorridas com o tratamento periodontal.

De modo geral, os parâmetros clínicos melhoraram com a terapia. Os que apresentaram melhores resultados foram PCS e SS $(p<0,05)$. A análise da literatura atual mostra que o uso de antibióticos sistêmicos pode melhorar os efeitos do tratamento periodontal não-cirúrgico nos casos de periodontite agressiva, principalmente com relação aos parâmetros clínicos (Herrera et al., 2002; Haffajee et al., 2003) e o presente estudo está de acordo com a literatura.

Apesar de observarmos uma melhora de todos os parâmetros clínicos estudados (PCS, LEC-MG, NCI, SS e IP), apenas o $\mathrm{NCl}$ não teve resultados estatisticamente significantes, o que difere do encontrado na literatura, que mostra que o parâmetro clínico mais favorecido com a associação de tratamento periodontal não-cirúrgico e antimicrobianos é o NCl (Haffajee et al., 2003). Isso pode ter ocorrido pelo fato da média inicial de $\mathrm{NCl}$ ter sido mais baixa em relação a outros estudos, o que pode ter levado a uma melhora, em média, menos significativa, pois a redução do $\mathrm{NCl}$ é mais marcante em sítios onde inicialmente o $\mathrm{NCl}$ é maior (Claffey; Egelberg, 1994).

A grande maioria dos estudos mais recentes que avaliam os efeitos clínicos e/ou microbiológicos do tratamento mecânico não-cirúrgico da PA utilizam a associação de algum antimicrobiano ao tratamento. O que ainda não se encontra na literatura é um protocolo definitivo que apresente o melhor momento da administração do antimicrobiano e a posologia mais adequada. Neste estudo, escolhemos a posologia de $500 \mathrm{mg}$ de amoxicilina a cada 8 horas durante 7 dias concomitante com $400 \mathrm{mg}$ de metronidazol a cada 8 horas durante 7 dias. Mestnik et al., 2010, utilizaram a mesma posologia. Os estudos diferem entre $500 \mathrm{mg} / 500 \mathrm{mg}$, de 8 em 8 horas por 7 dias (Guerrero et al., 2005; Xajigeorgiou et 
al., 2006; Guerrero et al., 2007) e 500mg/250mg, de 8 em 8 horas por 10 dias (Heller et al., 2011; Varela et al., 2011) de amoxicilina e metronidazol, respectivamente. Mas os resultados clínicos encontrados nos diferentes estudos não são diferentes. Loesche e Giordano (1994) mostraram que o uso de doses baixas de metronidazol (dose total de $4 \mathrm{~g}$ ) levam a resultados significativamente inferiores do que quando se usa doses totais maiores que $5,25 \mathrm{~g}$.

Com relação ao momento, escolhemos iniciar o uso dos antibióticos após o término dos procedimentos básicos e do período inicial de cicatrização (45 dias) para melhorar os efeitos do tratamento mecânico e facilitar a ação dos medicamentos após a desorganização e remoção do biofilme subgengival (van Winkelhoff et al., 1996; Socransky; Haffajee, 2002; AAP, 2004; Preshaw, 2004; Herrera et al., 2008; Mombelli, 2010). Mas, a grande maioria dos estudos mais recentes administrou o antibiótico no momento do início do tratamento mecânico (Yek et al., 2010; Griffiths et al., 2011) e com resultados satisfatórios para os casos de periodontite agressiva, mostrando melhora nos parâmetros clínicos pelo período de 6 meses (Kaner et al., 2007). Se fossemos determinar o antibiótico baseado em uma análise microbiológica, certamente o melhor momento seria após o término do tratamento mecânico, pois assim, haveria uma redução da carga bacteriana local e uma indicação e ação mais específicas do medicamento (Loesche e Giordano, 1994; Pavicic et al., 1994; AAP, 2004; Sigush et al., 2005) e, de acordo com uma revisão da literatura recente (Herrera et al., 2008), se o antimicrobiano for utilizado, o momento mais adequado para o início do uso é no final do procedimento de raspagem, que deve ser realizado com qualidade adequada.

Deas e Mealey, 2010, mostraram que existem alguns fatores, como baixa ocorrência da doença, e estudos com amostras pequenas, que levam a limitações ao conhecimento dos resultados dos diferentes tipos de tratamento periodontal da PA. Outras dificuldades são: tempo de raspagem, momento dos medicamentos, dosagem dos medicamentos, medicamentos mais indicados. Mas os autores discutem alguns estudos que mostraram resultados satisfatórios apenas com o tratamento mecânico não-cirúrgico, mas, resultados mais satisfatórios quando o tratamento mecânico não-cirúrgico foi associado aos antimicrobianos. 
Sigush et al., 2005, apresentaram resultados que mostram que a intensidade da instrumentação da superfície radicular foi um fator importante na manutenção dos resultados do tratamento, a longo prazo. No presente estudo foi estabelecido um protocolo de raspagem onde as superfícies radiculares foram instrumentadas mecanicamente com ultrassom e raspadores manuais até que fossem obtidas superfícies duras e lisas à sondagem. Consideramos que este protocolo se aproxima da realidade clínica vivida pelos profissionais, portanto não foram estabelecidos, previamente, o tempo de raspagem nem o numero de golpes do raspador por superfície radicular.

Os resultados microbiológicos encontrados no estudo após o uso dos antimicrobianos são semelhantes aos encontrados na literatura, com redução $(p<0,05)$ nas quantidades de T.d. e de T.f. após o tratamento mecânico nãocirúrgico associado ao antimicrobiano. Um tempo maior de acompanhamento seria importante para verificar a estabilidade das alterações microbiológicas. Estudos mostram que, após 12 meses, existe uma tendência de recorrência da quantidade dos microrganismos subgengivais (Valenza et al., 2009; Varela et al., 2011).

Após os procedimentos mecânicos, encontramos maiores quantidades de A.a. e D.p., mas estas alterações não foram significantes. Podemos sugerir que esse aumento pode ter ocorrido pela capacidade de invasão tecidual destas bactérias (Slots; Rosling, 1983). Johnson et al., 2008, mostraram que, devido à capacidade de invasão tecidual, existe uma manutenção de microrganismos nos sítios bucais mesmo após a terapia antimicrobiana com antibióticos sistêmicos e bochechos com clorexidina. Podemos sugerir, também, que, com a diminuição das quantidades dos outros microrganismos, o A.a., de alguma forma, foi favorecido. Este resultado é inédito, e outras avaliações, com amostras maiores, devem ser realizadas para confirmar os dados preliminares deste estudo, porque não foram encontrados estudos na literatura que tivessem realizado a quantificação absoluta pela qPCR dos microrganismos subgengivais em casos de PA tratados e portanto não temos como comparar esses resultados deste estudo. A maioria dos estudos recentes que avaliaram o tratamento periodontal da PA por hibridização DNA-DNA checkerboard mostraram diminuição nas quantidades destes microrganismos após a tratamento. 
A terapia estudada foi particularmente mais eficaz na redução de T.d. e T.f. $(p<0,05)$, e não se mostrou eficaz na redução de D.p. cuja quantidade aumentou, em relação ao início, após a terapia. Este resultado está de acordo com outros encontrados na literatura, que mostram que a terapia mecânica associada à terapia antimicrobiana é mais efetiva na redução dos microrganismos associados à doença periodontal mais grave (Haffajee et al., 1997; Heller et al., 2011; Rosalem et al., 2011; Yek et al., 2010). Apenas Heller et al. (2011) avaliaram a presença de D.p. em casos tratados de periodontite agressiva, com resultados semelhantes ao do presente estudo.

O controle das espécies patogênicas a longo prazo reside primariamente nas alterações do habitat. $O$ controle de patógenos subgengivais pode melhorar consideravelmente por meio da minimização de biofilme supragengival, da diminuição da inflamação gengival que fornece nutrientes para as espécies patogênicas e da diminuição da PCS que também serve como reservatório de patógenos (Socransky; Haffajee, 2010).

Dois estudos realizados com indivíduos portadores de periodontite crônica grave, que fizeram avaliação microbiológica através da PCR em tempo real (SYBR Green), sendo que um estudo comparou dois tratamentos: única sessão de desbridamento com ultrassom, associada à ingestão de placebo; e única sessão de desbridamento com ultrassom associada à ingestão de amoxicilina e metronidazol (Ribeiro et al., 2009); e o outro estudo comparou: raspagem e alisamento radicular, por quadrante; e única sessão de desbridamento com ultrassom (Del Peloso Ribeiro et al., 2008), não encontraram diferenças microbiológicas entre os tratamentos periodontais realizados, apesar de terem ocorrido reduções dos microrganismos durante os tratamentos.

A maior sensibilidade da GPCR mostrou que os principais periodontopatógenos podem ser encontrados em diferentes quantidades nas diversas formas de DP (Nonnenmacher et al., 2005; Lourenção, 2010). Pode-se considerar, então, que cada tipo de doença periodontal pode apresentar diferentes sorotipos da mesma bactéria ou, ainda, diferentes quantidades do microrganismo no ambiente subgengival. Essa quantificação também se mostra importante na avaliação dos resultados microbiológicos de diferentes formas de tratamento 
periodontal, como no presente estudo, em que apesar de não ocorrer a eliminação dos periodontopatógenos, houve uma melhora significativa dos parâmetros clínicos. Podemos questionar, então, a real necessidade de eliminação de certas espécies bacterianas para a obtenção de sucesso no tratamento periodontal. Este estudo vem, com uma metodologia mais específica e mais sensível, corroborar os resultados dos estudos que utilizaram hibridização DNA-DNA checkerboard (Socransky; Haffajee, 2010).

A PCR em tempo real mostrou-se bastante sensível e versátil para avaliação microbiológica de amostras subgengivais (Morillo et al., 2004), e as maiores vantagens desta técnica são as altas sensibilidade e especificidade (Boutaga et al., 2006). Optamos pela utilização das sondas TaqMan $\circledast$, que são mais específicas, e utilizamos, como controle positivo, curvas-padrão obtidas através de quantidades conhecidas de clones obtidos de cepas de referência (ATCC).

Faltam na literatura ensaios clínicos controlados que avaliem, pela qPCR, os resultados microbiológicos do tratamento periodontal não-cirúrgico associado a antimicrobianos, em casos de periodontite agressiva, pois a qPCR mostrou-se adequada para esta finalidade. 


\section{CONCLUSÕES}

Dentro dos limites do presente estudo, podemos concluir que:

Todos os parâmetros clínicos estudados, exceto $\mathrm{NCl}$, melhoraram após $\mathrm{O}$ tratamento mecânico não-cirúrgico associado ao uso de amoxicilina e metronidazol.

O tratamento mecânico não-cirúrgico da periodontite agressiva, associado a amoxicilina e metronidazol, reduziu significativamente as quantidades subgengivais de T.f. e T.d..

A qPCR foi adequada para a quantificação bacteriana dos casos tratados de PA. 


\section{REFERÊNCIAS ${ }^{1}$}

Akincibay H, Orsal SO, Sengun D, Tonzum TF. Systemic administration of doxycyclin versus metronidazole plus amoxicillin in the treatment of localized aggressive periodontitis: a clinical and microbiologic study. Quintessence Int. 2008 Feb;39(2):e33-9.

AAP - American Academy of Periodontology. International workshop for a classification of periodontal diseases and conditions. Ann Periodontol. 1999;4(1):2.

AAP - American Academy of Periodontology. Parameter on aggressive periodontites. J Periodontol. 2000;71:867-869

AAP - American Academy of Periodontology. Systemic antibiotics in periodontics (position paper). J Periodontol. 2004;75:1553-65.

Armitage GC. Comparison of the microbiological features of chronic and aggressive periodontitis. Periodontol 2000. 2010;53:70-88.

Armitage GC, Dickinson WR, Jenderseck RS, Levine SM, Chambers DW. Relationship between the percentage of subgingival spirochetes and the severity of periodontal disease. J Periodontol. 1982 Sep;53(9):550-6.

Asai $\mathrm{Y}$, Jinno T, Igarashi $\mathrm{H}$, Ohyama $\mathrm{Y}$, Ogawa T. Detection and quantification of oral treponemes in subgingival plaque by real-time PCR. J Clin Microbiol. 2002 Sep;40(9):3334-40.

Ashimoto A, Chen C, Bakker I, Slots J. Polymerase chain reaction detection of 8 putative periodontal pathogens in subgingival plaque of gingivitis and advanced periodontal lesions. Oral Microbiol Immunol. 1996;11:266-73.

Badersten A, Nilveus R, Egelberg J. Effect of nonsurgical periodontal therapy. I. Moderately advanced periodontitis. J Clin Periodontol. 1981 Feb;8(1):57-72.

${ }^{1}$ De acordo com estilo Vancouver 
Beck JD, Koch GG, Rozier RG, Tudor GE. Prevalence and risk indicators for periodontal attachment loss in a population of older community-dwelling blacks and whites. J Periodontol. 1990;61:521-8.

Beikler T, Prior K, Ehmke B, Flemming TF. Specific antibiotics in the treatment of periodontitis - a proposed strategy. J Periodontol. 2004;75(1):169-75.

Berglundh T, Krok L, Liljenberg B, Westfelt E, Serino G, Lindhe J. The use of metronidazole and amoxicillin in the treatment of advanced periodontal disease. A prospective, controlled clinical trial. J Clin Periodontol. 1998 May;25(5):354-62.

Boutaga K, van Winkelhoff AJ, Vandenbroucke-Grauls CMJE, Savelkoul PHM. The additional value of real-time PCR in the quantitative detection of periodontal pathogens. J Clin Periodontol. 2006;33:427-33.

Castillo DM, Sánchez-Beltrán MC, Castellanos JE, Sanz I, Mayorga-Fayad I, Sanz M, Lafaurie GI. Detection of specific periodontal microorganisms from bacteraemia samples after periodontal therapy using molecular-based diagnostics. J Clin Periodontol. 2011 May;38(5):418-27.

Chen C, Slots J. Microbiological tests for Actinobacillus actinomycetemcomitans and Porphyromonas gingivalis. Periodontol 2000. 1999;20:53-64.

Claffey N, Egelberg J. Clinical characteristics of periodontal sites with probing attachment loss following initial periodontal treatment. J Clin Periodontol. 1994 Nov;21(10):670-9.

Colombo AP, Boches SK, Cotton SL, Goodson JM, Kent R, Haffajee AD, Socransky SS, Hasturk H, Van Dyke TE, Dewhirst F, Paster BJ. Comparisons of subgingival microbial profiles of refractory periodontitis, severe periodontitis, and periodontal health using the human oral microbe identification microarray. J Periodontol. 2009 Sep;80(9):1421-32.

Contreras A, Doan N, Chen C, Rusitanonta T, Flynn MJ, Slots J. Importance of Dialister pneumosintes in human periodontitis. Oral Microbiol Immunol. 2000; (15):269-72. 
Corless CE, Guiver M, Borrow R, Edwards-Jones V, Fox AJ, Kaczmarski EB. Simultaneous detection of Neisseria meningitidis, Haemophilus influenzae, and Streptococcus pneumoniae in suspected cases of meningitis and septicemia using real-time PCR. J Clin Microbiol. 2001 Apr;39(4):1553-8.

Cortelli JR, Cortelli SC, Jordan S, Haraszthy VI, Zambon JJ. Prevalence of periodontal pathogens in Brazilians with aggressive or chronic periodontits. J Clin Periodontol. 2005;32:860-6.

Dangtuan ST, Rudney JD. Multiplex PCR using conserved and species-specific $16 \mathrm{~S}$ rRna gene primers for simultaneous detection of Actinobacillus actinomycetemcomitans and Porphyromonas gingivalis. J Clin Microbiol. 1996;34:2674-8.

Dawson MT, Powell R, Gannon F. Gene technology. Oxford: BIOS Scientific Publishers; 1996.

De Graaff J, van Winkelhoff AJ, Goené RJ. The role of Actinobacillus actinomycetemcomitans in periodontal disease. Infection. 1989 Jul-Aug;17(4):26971.

Deas DE, Mealey BL. Response of chronic and aggressive periodontites to treatment. Periodontol 2000. 2010;53:154-66.

Del Peloso Ribeiro E, Bittencourt S, Sallum EA, Nociti FH Jr, Gonçalves RB, Casati MZ. Periodontal debridement as a therapeutic approach for severe chronic periodontits: a clinical, microbiological and immunological study. J Clin Periodontol. 2008 Sep;35(9):789-98.

Doan N, Contreras A, Chen C, Flynn MJ, Slots J. Molecular identification of Dialister pneumosintes in subgingival plaque of humans. J Clin Microbiol. 2000;(38):3043-47.

Doungudomdacha S, Rawlinson A, Walsh TF, Douglas CWI. Effect of non-surgical periodontal treatment on clinical parameters and the numbers of Porphyromonas gingivalis, Prevotella intermedia and Actinobacillus actinomycetemcomitans at adult periodontitis sites. J Clin Periodontol. 2001;28:437-45. 
Ehmke B, Moter A, Beikler T, Milian E, Flemmig TF. Adjunctive antimicrobial therapy of periodontitis: long-term effects on disease progression and oral colonization. J Periodontol. 2005 May;76(5):749-59.

Faveri M, Figueiredo LC, Duarte PM, Mestnik MJ, Mayer MP, Feres M. Microbiological profile of untreated subjects with localized aggressive periodontitis. J Clin Periodontol. 2009 Sep;36(9):739-49.

Feres M, Gonçalves C. O impacto do diagnóstico microbiológico na terapêutica periodontal. In: Oppermann RV, Rösing CK. Periodontia: ciência e clínica. 1a. ed. São Paulo: Artes Médicas; 2001. Cap. 2.3, p.39-56.

Feres M, Haffajee AD, Allard K, Som S, Socransky SS. Change in subgingival microbial profiles in adult periodontitis subjects receiving either systemicallyadministered amoxicillin or metronidazole. J Clin Periodontol. 2001 Jul;28(7):597609.

Feres M. Antibiotics in the treatment of periodontal diseases: microbiological basis and clinical applications. Ann R Australas Coll Dent Surg. 2008 Jun;19:37-44.

García L, Tercero JC, Legido B, Ramos JA, Alemany J, Sanz M. Rapid detection of Actinobacillus actinomycetemcomitans, Prevotella intermedia and Porphyromonas gingivalis by multiplex PCR. J Periodont Res. 1998;33:59-64.

Genco R, Kornman K, Williams R, Offenbacher S, Zambom JJ, Listgarten M, Michalowicz B, Page R, Schenkein H, Slots J, Socransky S, Van Dyke T. Consensus report periodontal diseases: pathogenesis and microbial factors. Ann Periodontol. 1996;1:926-32.

Ghayoumi N, Chen C, Slots J. Dialister pneumosintes, a new putative periodontal pathogen. J Periodont Res. 2002;(37):75-78.

Greenstein G. Microbiologic assessments to enhance periodontal diagnosis. J Periodontol. 1988;59:508-15.

Griffiths GS, Ayob R, Guerrero A, Nibali L, Suvan J, Moles DR, Tonetti MS. Amoxicillin and metronidazole as an adjunctive treatment in generalized 
aggressive periodontitis at initial therapy or retreatment: a randomized controlled clinical trial. J Clin Periodontol. 2011 Jan;38(1):43-9.

Guerrero A, Echeverria JJ, Tonetti MS. Incomplete adherence to an adjunctive systemic antibiotic regimen decreases clinical outcomes in generalized aggressive periodontitis patients: a pilot retrospective study. J Clin Periodontol. 2007 Oct;34(10):897-902.

Guerrero A, Griffiths GS, Nibali L, Suvan J, Moles DR, laurel L, Tonetti MS. Adjunctive benefits of systemic amoxicillin and metronidazole in non-surgical treatment of generalized aggressive periodontitis: a randomized placebo-controlled clinical trial. J Clin Periodontol. 2005 Oct;32(10):1096-107.

Haas AN, de Castro GD, Moreno T, Susin C, Albandar JM, Oppermann RV, Rosing CK. Azithromycin as an adjunctive treatment of aggressive periodontitis: 12-months randomized clinical trial. J Clin Periodontol. 2008 Aug; 5(8):696-704.

Haffajee AD, Cugini MA, Dibart S, Smith C, Kent RL, Socransky SS. The effect of SRP on the clinical and microbiological parameters of periodontal diseases. J Clin Periodontol. 1997;24:324-34.

Haffajee AD, Socransky SS, Gunsolley JC. Systemic anti-infective periodontal therapy. A systematic review. Ann Periodontol. 2003 Dec;8(1):115-81.

Haffajee AD, Uzel NG, Arguello El, Torresyap G, Guerrero DM, Socransky SS. Clinical and microbiological changes associated with the use of combined antimicrobial therapies to treat "refractory" periodontitis. J Clin Periodontol. 2004 Oct;31(10):869-77.

Hartroth B, Seyfahrt I, Conrads G. Sampling of periodontal pathogens by paper points: evaluation of basic parameters. Oral Microbiol Immunol. 1999;14(5):326-30.

Heller D, Varela VM, Silva-Senem MX, Torres MC, Feres-Filho EJ, Colombo AP. Impact of systemic antimicrobials combined with anti-infective mechanical debridement on the microbiota of generalized aggressive periodontitis: a 6-month RCT. J Clin Periodontol. 2011 Apr;38(4):335-64. 
Henegariu O, Heerema NA, Dlouhy SR, Vance GH, Vogt PH. Multiplex PCR: critical parameters and step-by-step protocol. Biotechniques. 1997;23:504-11.

Herrera D, Alonso B, Léon R, Roldán S, Sanz M. Antimicrobial therapy in periodontitis: the use of systemic antimicrobials against the subgingival biofilm. $J$ Clin Periodontol. 2008 Sep;35 suppl 8:45-66.

Herrera D, Sanz M, Jepsen S, Needleman I, Roldán S. A systematic review on the effect of systemic antimicrobials as an adjunct to scaling and root planning in periodontitis patients. J Clin Periodontol. 2002;29 suppl 3:136-59.

Jebbink J, Bai X, Rogers BB, Dawson DB, Scheuermann RH, Dominiati-Saad R. Development of Real-Time PCR Assays for the Quantitative Detecton of EpsteinBarr Virus and Cytomegalovirus, Comparation of TaqMan Probes, and Molecular Beacons, J Molec Diagnost. 2003;5(1):110-16.

Jervøe-Storm PM, Koltzscher M, Falk W, Dörfler A, Jepsen S. Comparison of culture and real-time PCR for detection and quantification of five putative periodontopathogenic bacteria in subgingival plaque samples. J Clin Periodontol. 2005 Jul;32(7):778-83.

Johnson JD, Chen R, Lenton PA, Zhang G, Hinrichs JE, Rudney JD. Persistence of extracrevicular bacterial reservoirs after treatment of aggressive periodontitis. J Periodontol. 2008 Dec;79(12):2305-12.

Kaner D, Christan C, Dietrich T, Bernimoulin JP, Kleber BM, Friedmann A. Timing affects the clinical outcome of adjunctive systemic antibiotic therapy for generalized aggressive periodontitis. J Periodontol. 2007 Jul;78(7):1201-8.

Kubar A, Saygun I, Yapar M, Ozdemir A, Slots J. Real-time PCR quantification of cytomegalovirus in aggressive periodontitis lesions using TaqMan technology. J Periodontal Res. 2004 Apr;39(2):81-6.

Kuboniwa M, Amano A, Kimura KR, Sekine S, Kato S, Yamamoto Y, Okahashi N, lida T, Shizukuishi S. Quantitative detection of periodontal pathogens using realtime polymerase chain reaction with TaqMan probes. Oral Microbiol Immunol. 2004;19(3):168-76. 
Lamster IB, Celenti RS, Jans HH, Fine JB, Grbic JT. Current status of tests for periodontal disease. Advan Dent Res. 1993;7:182-90.

Lau L, Sanz M, Herrera D, Morillo JM, Martín C, Silva A. Quantitative real-time polymerase chain reaction versus culture: a comparison between two methods for detection and quantification of Actinobacillus actinomycetemcomitans, Porphyromonas gingivalis and Tannerella forsythensis in subgingival plaque samples. J Clin Periodontol. 2004;31:1061-9.

Lindhe J, Nyman S. Long-term maintenance of patients treated for advanced periodontal disease. J Clin Periodontol. 1984 Sep;11(8):504-14.

Listgarten MA, Levin S. Positive correlation between the proportions of subgingival spirochetes and motile bacteria and susceptibility of human subjects to periodontal deterioration. J Clin Periodontol. 1981 Apr;8(2):122-38.

Löe H, Silness J. Periodontal disease in pregnancy. I. Prevalence and severity. Acta Odontologica Scandinavia. 1963;21:533-51.

Loesche WJ. Chemoterapy of dental plaque infections. Oral Sci Rev. 1976;(9):65107.

Loesche WJ, Giordano JR. Metronidazole in periodontitis V: debridement should precede medication. Compendium. 1994 Oct;15(10):1198,1201,1203 passim;quiz 1218.

Loesche WJ, Giordano J, Hujoel PP. The utility of the BANA test for monitoring anaerobic infections due to spirochetes (Treponema denticola) in periodontal disease. J Dent Res. 1990 Oct;69(10):1696-702.

Loomer PM. Microbiological diagnostic testing in the treatment of periodontal diseases. Periodontol 2000. 2004;34:49-56.

Lotufo R, Pannuti CM. Recursos para o diagnóstico microbiológico em periodontia. In: Oppermann RV, Rösing CK. Periodontia: ciência e clínica. 1a. ed. São Paulo: Artes Médicas; 2001. Cap. 2.2, p.31-8. 
Lotufo RFM, Pannuti CM, Rodrigues AS. Diagnóstico microbiológico: evidências científicas para a prática clínica. In: Almeida RV. Periodontia. A atuação clínica baseada em evidências científicas. São Paulo: Artes Médicas; 2005. V.1. Cap. 5. p. 73-84.

Lourenção DS. Detecção e quantificação de bactérias no biofilme subgengival de indivíduos com diferentes formas de doença periodontal [dissertação]. São Paulo: Universidade de São Paulo, Faculdade de Odontologia; 2010.

Lyons SR, Griffen AL, Leys EJ. Quantitative real-time PCR for Porphyromonas gingivalis and total bacteria. J Clin Microbiol. 2000 Jun;38(6):2362-5.

Machtei EE, Younis MN. The use of 2 antibiotic regimens in aggressive periodontitis: comparison of changes in clinical parameters and gingival crevicular fluid biomarkers. Quintessence Int. 2008 Nov;39(10): 811-9.

Mackay IM. Real-time PCR in the microbiology laboratory. Clin Microbiol Infect. 2004 Mar;10(3):190-212. Review.

Mario A, Federica R, Nicoletta G, Carnevale G. One-stage full-mouth disinfection as a therapeutic approach for generalized aggressive periodontitis. J Periodontol. 2010. Posted online on Nov 23. doi:10.1902/jop.2010.100468.

Mestnik MJ, Feres M, Figueiredo LC, Duarte PM, Lira EA, Faveri M. Short-term benefits of the adjunctive use of metronidazole plus amoxicillin in the microbial profile and in the clinical parameters of subjects with generalied aggressive periodontitis. J Clin Periodontol. 2010 Apr;37(4): 353-65.

Michalowicz BS, Ronderos M, Camara-Silva R, Contreras A, Slots J. Human herpesviruses and Porphyromonas gingivalis are associated with early-onset periodontitis. J Periodontol. 2000;71:981-8.

Mombelli A, Samaranayake LP. Topical and systemic antibiotics in the management of periodontal diseases. Int Dent J. 2004 Feb;54(1):3-14.

Mombelli A. Antibióticos na terapia periodontal. In: Lindhe J, Lang NP, Karring T. Tratado de periodontia clínica e implantologia oral. $5^{a}$. ed. Rio de Janeiro: Guanabara Koogan; 2010. Cap. 42. p.848-62. 
Moore LVH, Moore WEC. Oribaculum cantoniae gen. nov., sp. nov.; Catonella morbi gen. nov., sp. nov.; Hallella seregens gen. nov., sp. nov.; Johnsonella ignava gen. nov., sp. nov.; and Dialister pneumosintes gen. nov., comb. nov., nom. Rev., annaerobic gram-negative bacilli from the human gingival crevice. Int J Syst Bacteriol. 1994a;(44):187-92.

Moore WEC, Moore LVH. The bacteria of periodontal diseases. Periodontol 2000. 1994b;(5):66-77.

Morillo JM, Lau L, Sanz M, Herrera D, Martin C, Silva A. Quantitative real-time PCR based on single copy gene sequence for detection of periodontal pathogens. J Clin Periodontol. 2004;31:1054-60.

Morillo JM, Lau L, Sanz M, Herrera D, Silva A. Quantitative real-time PCR based on single copy gene sequence for detection of Actinobacillus actinomycetemcomitans and Porphyromonas gingivalis. J Periodontal Res. 2003 Oct;38(5):518-24.

Newman MG, Socransky SS, Savitt ED, Propas DA, Crawford A. Studies of the microbiology of periodontosis. J Periodontol. 1976;47(7):373-9.

Nicholl DST An introduction to genetic engineering. Cambridge: Cambridge University Press;1994.

Nonnenmacher C, Dalpke A, Mutters R, Heeg K. Quantitative detection of periodontopathogens by real-time PCR. J Microbiol Methods. 2004;59(1):117-25.

Nonnenmacher C, Dalpke A, Rochon J, Flores-de-Jacoby L, Mutters R, Heeg K. Real-time polymerase chain reaction for detection and quantification of bacteria in periodontal patients. J Periodontol. 2005;76(9):1542-9.

Novaes AB Jr, Schwartz-Filho HO, de Oliveira RR, Feres M, Sato S, Figueiredo LC. Antimicrobial photodynamic therapy in the non-surgical treatment of aggressive periodontitis: microbiological profile. Lasers Med Sci. 2011 Mar 12. Epub ahead of print. 
O'Leary TJ, Drake RB, Naylor JE. The plaque control record. J Periodontol. 1972; 43(1):38.

Paster BJ, Boches SK, Galvin JL, et al. Bacterial diversity in human subgingival plaque. J Bacteriol. 2001;183:3770-83.

Pavicić MJ, van Winkelhoff AJ, Douqué NH, Steures RW, de Graaff J. Microbiological and clinical effects of metronidazole and amoxicillin in Actinobacillus actinomycetemcomitans-associated periodontitis. A 2-year evaluation. J Clin Periodontol. 1994 Feb;21(2):107-12.

Pihlstrom BL, McHugh RB, Oliphant TH, Ortiz-Campos C. Comparison of surgical and nonsurgical treatment of periodontal disease. A review of current studies and additional results after 61/2 years. J Clin Periodontol. 1983 Sep;10(5):524-41.

Preshaw PM. Antibiotics in the treatment of periodontitis. Dent Update. 2004 Oct; 31(8):448-50, 453-3, 456.

Ribeiro E del P, Bittencourt S, Zanin IC, Bovi Ambrosano GM, Sallum EA, Nociti $\mathrm{FH}$, Gonçalves RB, Casati MZ. Full-mouth ultrasonic debridement associated with amoxicillin and metronidazole in the treatment of severe chronic periodontites. $J$ Periodontol. 2009 Aug;80(8):1254-64.

Rolain JM, Mallet MN, Fournier PE, Raoult D. Real-time PCR for universal antibiotic susceptibility testing. J Antimicrob Chemother. 2004;54(2):538-41.

Rosalem W, Rescala B, Teles RP, Fischer RG, Gustafsson A, Figueiredo C. Effect of non-surgical treatment on chronic and aggressive periodontitis: clinical, immunological and microbial findings. J Periodontol. 2011. Posted online on Feb. doi:10.1902/jop.2011.100579.

Saarela MH, Dogan B, Alaluusua S, Asikainen S. Persistence of oral colonizations by the same Actinobacillus actinomycetemcomitans strain(s). J Periodontol. 1999 May;70(5):504-9.

Sambrook J, Russel DW. Molecular cloning: a laboratory manual. 3. ed. Cold Spring Harbor: Cold Spring Harbor Laboratory Press; 2001. 
Sanz M, Lau L, Herrera D, Morillo JM, Silva A. Methods of detection of Actinobacillus actinomycetemcomitans, Porphyromonas gingivalis and Tannerella forsythensis in periodontal microbiology, with special emphasis on advanced molecular techniques: a review. J Clin Periodontol. 2004;31:1034-47.

Sigusch BW, Guntsch A, Pfitzner A, Glockmann E. Enhanced root planing and systemic metronidazole administration improve clinical and microbiological outcomes in a two-step treatment procedure. J Periodontol. 2005 Jun;76(6):991-7.

Skipper M, Johansen LB, Pedersen KB, Frederiksen S, Johansen BB. Cloning and transcription analysis of an AGAMOUS- and SEEDSTICK ortholog in the orchid Dendrobium thyrsiflorum (Reichb. f.). Gene. 2006 Feb;1;366(2):266-74.

Slots J, Feik D, Rams TE. Prevalence and antimicrobial susceptibility of Enterobacteriaceae, Pseudomonadaceae and Acinetobacter in human periodontitis. Oral Microbiol Immunol. 1990;5(3):149-54.

Slots J, Jorgensen MG. Effective, safe, practical and affordable periodontal antimicrobial therapy: where are we going, and are we there yet? Periodontol 2000. 2002;28:298-312.

Slots J, Rosling B. Suppressionof the periodontopathogenic microflora in localised juvenile periodontitis by systemic tetracycline. J Clin Periodontol. 1983;10:465-86.

Slots J, Ting M. Systemic antibiotics in the treatment of periodontal disease. Periodontol 2000. 2002;28:106-76.

Slots J. Herpesviruses in periodontal diseases. Periodontol 2000. 2005;28:33-62.

Slots J. Selection of antimicrobial agents in periodontal therapy. J Periodontal Res. 2002;37:389-98.

Slots J. The predominant cultivable microflora of advanced periodontitis. Scand J Dent Res. 1977;85(2):114-21. 
Socransky SS, Haffajee AD, Cugini MA, Smith C, Kent RL Jr. Microbial complexes in subgingival plaque. J Clin Periodontol. 1998;25:134-44.

Socransky SS, Smith C, Haffajee AD. Subgingival microbial profiles in refractory periodontal disease. J Clin Periodontol. 2002;29:260-8.

Socransky SS, Haffajee AD, Smith C, Martin L, Haffajee JA, Uzel NG, Goodson JM. Use of checkerboard DNA-DNA hybridization to study complex microbial ecosystems. Oral Microbiol Immunol. 2004 Dec;19(6):352-62.

Socransky SS, Haffajee AD. Dental biofilms: difficult therapeutic targets. Periodontol 2000. 2002;28:12-55.

Socransky SS, Haffajee AD. Infecções periodontais. In: Lindhe J, Lang NP, Karring T. Tratado de periodontia clínica e implantologia oral. $5^{\text {a }}$. ed. Rio de Janeiro: Guanabara Koogan; 2010. Cap.9. p. 197-254.

Socransky SS, Haffajee AD. Microbiologia da doença periodontal. In: Lindhe J, Karring T, Lang NP. Tratado de periodontia clínica e implantologia oral. $3^{\mathrm{a}}$. ed. Trad. de Edson JL. Moreira. Rio de Janeiro: Guanabara Koogan; 1999. Cap.4.p.92-126.

Socransky SS, Smith C, Martin L, Paster BJ, Dewhirst FE, Levin AE. "Checkerboard" DNA-DNA hybridization. Biotechniques. 1994 Oct;17(4):788-92.

Soder PO, Jin LJ, Soder B. DNA probe detection of periodontopathogens in advanced periodontitis. Scand J Dent Res. 1993;101(6):363-70.

Ting M, Contreras A, Slots J. Herpesviruses in localized juvenile periodontitis. J Periodontal Res. 2000;35:17-25.

Tinoco EM, Beldi MI, Campedelli F, Lana M, Loureiro CA, Bellini HT, Rams TE, Tinoco NM, Gjermo P, Preus HR. Clinical and microbiological effects of adjunctive antibiotics in treatment of localized juvenile periodontitis. A controlled clinical trial. J Periodontol. 1998 Dec;69(12):1355-63. 
Tonetti MS, Mombelli A. Periodontite Agressiva. In: Lindhe J, Karring T, Lang NP Tratado de periodontia clínica e implantologia oral. 5a. ed. Rio de Janeiro: Guanabara Koogan; 2010. Cap. 19. p. 410-38.

Tsai CY, Wolff LF, Germaine G, Hodges J. A rapid DNA probe test compared to culture methods for identification of subgingival plaque bacteria. J Clin Periodontol. 2003;30:57-62.

Umeda M, Chen C, Bakker I, Contreras A, Morrison JL, Slots J. Risk indicators for harboring periodontal pathogens. J Periodontol. 1998;69:1111-8.

Valenza G, Veihelmann S, Peplies J, Tichy D, Roldan-Pareja MC, Schlagenhauf U, Vogel U. Microbial changes in periodontitis successfully treated by mechanical plaque removal and systemic amoxicillin and metronidazole. Int J Med Microbiol. 2009 Aug;299(6):427-38. Epub 2009 May 15.

van Winkelhoff AJ, Rams TE, Slots J. Systemic antibiotic therapy in periodontics. Periodontol 2000. 1996 Feb;10:45-78.

van Winkelhoff AJ, Rodenburg JP, Goené RJ, Abbas F, Winkel EG, de Graaff J. Metronidazole plus amoxycillin in the treatment of Actinobacillus actinomycetemcomitans associated periodontitis. J Clin Periodontol. 1989 Feb;16(2):128-31.

van Winkelhoff AJ, Tijhof CJ, de Graaff J. Microbiological and clinical results of metronidazole plus amoxicillin in Actinobacillus actinomycetemcomitansassociated periodontitis. J Periodontol. 1992;63:52-7.

Varela VM, Heller D, Silva-Senem MX, Torres MC, Colombo AP, Feres-Filho EJ. Systemic antimicrobials adjunctive to a repeated mechanical and antiseptic therapy for aggressive periodontitis: a 6-month randomized controlled trial. J Periodontol. 2011. Posted online on Jan. doi:10.1902/jop.2011.100656.

Verner C, Lemaitre P, Daniel A, Giumelli B, Lakhssassi N, Sixou M. Carpegen realtime polymerase chain reaction vs. anaerobic culture for periodontal pathogen identification. Oral Microbiol Immunol. 2006 Dec;21(6):341-6.

Walker C, Karpinia K. Rationale for use of antibiotics in periodontics. J Periodontol. 
2002 Oct;73(10):1188-96.

Winkel EG, Van Winkelhoff AJ, Timmerman MF, Van der Velden U, Van der Weijden GA. Amoxicillin plus metronidazole in the treatment of adult periodontitis patients. A double-blind placebo-controlled study. J Clin Periodontol. 2001 Apr;28(4):296-305.

Xajigeorgiou C, Sakellari D, Slini T, Baka A, Konstantinidis A. Clinical and microbiological effects of different antimicrobials on generalized aggressive periodontitis. J Clin Periodontol. 2006 Apr;33(4):254-64.

Xymenez-Fyvie LA, Haffajee AD, Socransky SS. Microbial composition of supra and subgingival plaque in subjects with adult periodontitis. J Clin Periodontol. 2000;27:722-32.

Yek EC, Cintan S, Topcuoglu N, Kulekci G, Issever H, Kantarci A. Efficacy of amoxicillin and metronidazole combination for the management of generalized aggressive periodontitis. J Periodontol. 2010 Jul;81(7):964-74.

Yoshida A, Kawada M, Suzuki N, Nakano Y, Oho T, Saito T, Yamashita Y. TaqMan real-time polymerase chain reaction assay for the correlation of Treponema denticola numbers with the severity of periodontal disease. Oral Microbiol Immunol. 2004 Jun;19(3):196-200.

Zambon JJ, Haraszthy VI. The laboratory diagnosis of periodontal infections. Periodontol 2000. 1995;7:69-82.

Zambon JJ, Christersson LA, Genco RJ. Diagnosis and treatment of localized juvenile periodontitis. J Am Dent Assoc. 1986 Aug;113(2):295-9.

Zambon JJ. Principles of evaluation of the diagnostic value of subgingival bacteria. Ann Periodontol. 1997;2:138-48. 
ANEXO A - Termo de consentimento livre e esclarecido

\section{TERMO DE CONSENTIMENTO LIVRE E ESCLARECIDO}

Este TERMO DE CONSENTIMENTO LIVRE E ESCLARECIDO tem a finalidade de convidá-lo(a) à participação em uma pesquisa entitulada "ANTIBIOTICOTERAPIA BASEADA EM DIAGNÓSTICO MICROBIOLÓGICO NO TRATAMENTO NÃO-CIRÚRGICO DE PERIODONTITE AGRESSIVA" que tem como objetivo verificar a presença de bactérias na sua gengiva, mais especificamente na bolsa periodontal, e a eficiência do tratamento periodontal e de alguns antibióticos no tratamento de periodontite agressiva.

Para a realização desta pesquisa a SUA PARTICIPAÇÃO É MUITO IMPORTANTE, mas, para que isso ocorra, é necessária a SUA AUTORIZAÇÃO, uma vez que realizaremos exames clínicos e trataremos os seus dentes, o que pode provocar um pequeno incômodo. Além disso, você será medicado(a) com antibióticos, mas, se houver alguma reação indesejável durante o tratamento, as devidas providências serão tomadas, não causando prejuízo aos resultados do seu tratamento.

Todos os procedimentos que serão realizados seguem abaixo, sendo que NENHUM DELES IRÁ PROVOCAR DANOS À SUA SAÚDE:

1)Anamnese;

2)Exame clínico periodontal (preenchimento de periograma);

3)Evidenciação de placa bacteriana;

4)Coleta de biofilme subgengival com pontas de papel;

5)Orientação de higiene bucal;

6)Tratamento periodontal completo;

7)Administração de antibióticos;

8)Encaminhamento para o tratamento de outras doenças bucais, se necessário.

Esses procedimentos são de rotina em qualquer tratamento de periodontite agressiva, causando um desconforto esperado em qualquer tratamento periodontal. 
Todos os participantes receberão atendimento, durante o estudo, nas dependências da Faculdade de Odontologia da USP e, caso necessitem de outros tratamentos odontológicos, serão encaminhados para atendimento na FOUSP.

Após ler e compreender completamente todos os passos descritos (e, se não compreendeu, solicite mais explicações), favor assinar a autorização abaixo, SE ISSO FOR DE SUA VONTADE:

Eu, , LI e

ENTENDI os procedimentos que serão realizados, ACEITO a participação na pesquisa "ANTIBIOTICOTERAPIA BASEADA EM DIAGNÓSTICO MICROBIOLÓGICO NO TRATAMENTO NÃO-CIRÚRGICO DE PERIODONTITE AGRESSIVA" e AUTORIZO a utilização dos dados coletados. Estou ciente de todos os procedimentos e que estes serão realizados na clínica da Faculdade de Odontologia da USP, e que, no caso de qualquer intercorrência, as devidas providências serão tomadas e não haverá prejuízo no resultado o tratamento.

Fui informado(a) que receberei o tratamento periodontal adequado para o meu caso.

Sei ainda que PODEREI DESISTIR DA PESQUISA A QUALQUER MOMENTO, mesmo após ter assinado este Termo, sem sofrer qualquer penalização ou prejuízo do tratamento. Também ficou claro que não terei qualquer compensação financeira por participar desta pesquisa. 
Os dados coletados serão usados apenas nesta pesquisa e qualquer um relacionado à minha identidade permanecerá em sigilo.

Se houver dúvidas sobre a ética da pesquisa, entre em contato com o COMITÊ DE ÉTICA EM PESQUISA DA FACULDADE DE ODONTOLOGIA (Av. Prof. Lineu Prestes, 2227, 05508-000 - São Paulo).

São Paulo, _ de de_ de 200_. 


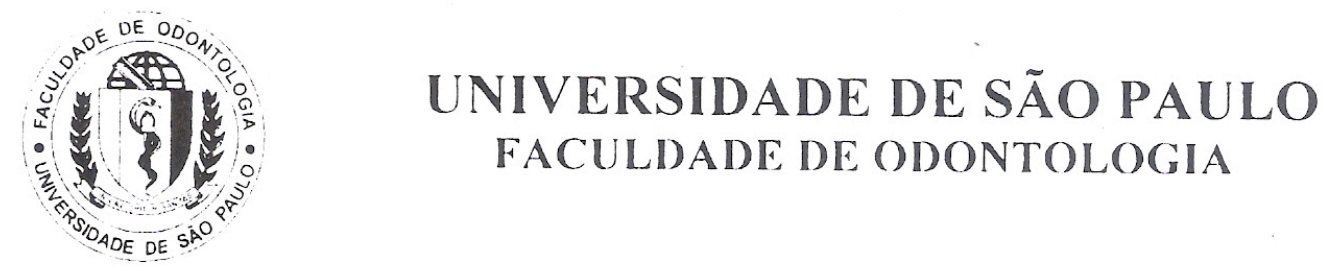

\section{PARECER DE APROVAÇÃO Protocolo 170/05}

Com base em parecer de relator, o Comitê de Ética em Pesquisa, APROVOU o protocolo de pesquisa "Antibioticoterapia baseada em diagnóstico microbiológico no tratamento não-cirúrgico de periodontite agressiva", de responsabilidade da Pesquisadora Ariana Soares Rodrigues, sob orientação do Professor Doutor Roberto Fraga Moreira Lotufo.

Tendo em vista a legislação vigente, devem ser encaminhados a este Comitê relatórios anuais referentes ao andamento da pesquisa e ao término cópia do trabalho em "cd". Qualquer emenda do projeto original deve ser apresentada a este CEP para apreciação, de forma clara e sucinta, identificando a parte do protocolo a ser modificada e suas justificativas.

São Paulo, 07 de dezembro de 2005

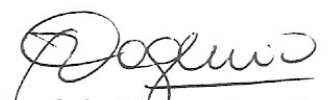

Prof.Dr. Rogério Nogueira de Oliveira Coordenador do CEP-FOUSP 


\section{ANEXO C - Ficha de anamnese}

\section{SAÚDE GERAL}

1. Está em tratamento médico?

2. Foi submetido a alguma cirurgia?

sim ( ) não ( )

3. Teve alguma destas doenças:

- Hepatites

- Tuberculose

- Ataque Cardíaco

- Diabetes

- Febre Reumática

4. Toma anticoagulante (AAS)?

5. É fumante? Sim ( ) não ( ) Quantos?...........

6. Pressão alta?

7. Sofre dos rins ou bexiga?

8. Tem com freqüência algum tipo de hemorragia

$\operatorname{sim}($ ) não ( )

9. Aparecem manchas roxas no corpo com freqüência

sim ( ) não ( )

sim ( ) não ( )

$\operatorname{sim}($ ) não ( )

$\operatorname{sim}($ ) não ( )

$\operatorname{sim}$ ( ) não ( )

$\operatorname{sim}($ ) não ( )

10.Anemia?

11.Tem alguma alergia?

12.Alergia a quê?

13.Já recebeu transfusão de sangue?

14. Tem doença sexualmente transmissivel (AIDS)

sim ( ) não ( )

$\operatorname{sim}($ ) não ( )

sim ( ) não ( )

sim ( ) não ( )

sim ( ) não ( )

$\operatorname{sim}($ ) não ( )

sim ( ) não ( )

sim ( ) não ( )

sim ( ) não ( )

sim ( ) não ( )

$\operatorname{sim}($ ) não ( )

$\operatorname{sim}($ ) não ( )

sim ( ) não ( )

$\operatorname{sim}($ ) não ( )

17. Menstruação normal?

18.Está grávida?

19. Toma anticoncepcional?

20.Está na menopausa?

21.Medicamento em uso:

sim ( ) não ( )

\section{PARTE ODONTOLÓGICA}

1 Queixa do Paciente:

\begin{tabular}{|c|c|c|}
\hline 2 & Já teve feridas nos lábios ou língua que demoraram para sarar? & $\operatorname{sim}($ ) não ( ) \\
\hline 3 & Come muito doce? $\operatorname{sim}($ ) não ( ) Refrigerantes: & $\operatorname{sim}($ ) não ( ) \\
\hline 4 & Tem hábito de ranger ou apertar os dentes? & sim ( ) não ( ) \\
\hline 5 & Tem sangramento gengival? & sim ( ) não ( ) \\
\hline 6 & Tem dor nas gengivas? & sim ( ) não ( ) \\
\hline 7 & Tem dentes abalados? & sim ( ) não ( ) \\
\hline 8 & Quantas vezes por dia escova os dentes? & sim ( ) não ( ) \\
\hline $\begin{array}{l}9 \\
10\end{array}$ & $\begin{array}{l}\text { Usa escova: dura ( ) média ( ) mole ( ) } \\
\text { Utiliza fio ou fita dental? }\end{array}$ & sim ( ) não ( ) \\
\hline 11 & Quantas vezes por dia? .................. & \\
\hline 12 & Usa outros métodos de limpeza? & $\operatorname{sim}($ ) não ( ) \\
\hline 13 & Quais? ...................................... não ( & \\
\hline $\begin{array}{l}14 \\
15\end{array}$ & $\begin{array}{l}\text { Bochechos? Sim ( ) não ( ) Q } \\
\text { Já fez aplicação tópica de flúor? }\end{array}$ & sim ( ) não ( ) \\
\hline
\end{tabular}


FICHA. INICIAL ( ) REAVALIAÇÃO( ) FINAL ( )

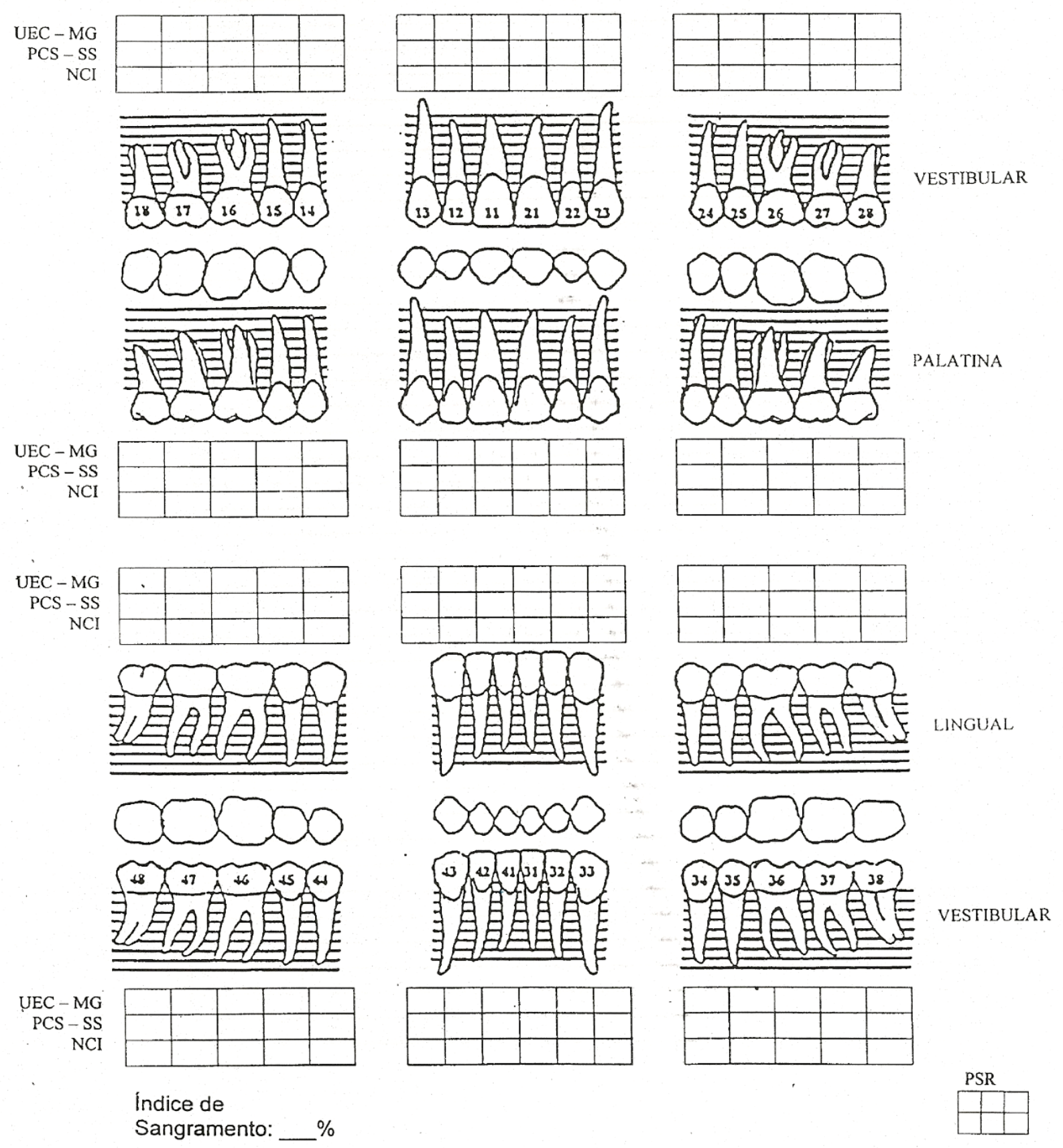

